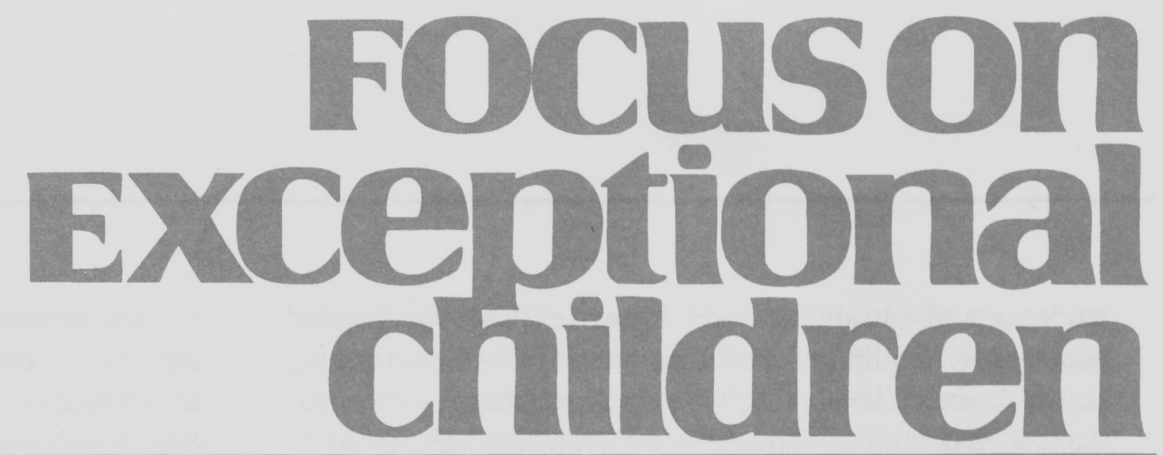

\title{
Accessing the General Education Math Curriculum for Secondary Students With High-Incidence Disabilities
}

\author{
Paula Maccini, Tricia Strickland, Joseph Calvin Gagnon, and Kimber Malmgren
}

Both international and national assessments indicate that secondary students in the United States experience difficulty in learning mathematics and score below many of their international counterparts. In particular, data from two international educational assessments, the Trends in International Mathematics and Science Study (Gonzales et al., 2004) and the Program for International Student Assessment (Baldi, Jin, Skemer, Green, \& Herget, 2007), show that students in the United States are performing below the level of many other industrialized countries in mathematics. Policy makers, educators, and parents use outcomes from TIMSS and PISA to determine the quality of the U.S. education system and to predict the success of the United States in the global economy (Bybee \& Stage, 2005). The data from these assessments suggest that the U.S. education system is not providing students the conceptual knowledge and real-world problem-solving skills necessary to compete in the world market.

The mathematics performance of secondary students within the United States raises additional concerns. For example, the National Assessment of Educational Progress (NAEP) showed that $30 \%$ of students in eighth grade scored below a basic achievement level, with "basic" defined as partial mastery of knowledge and skills. This result means that more than one quarter of the eighth-grade students did not demonstrate even partial mastery of the mathematics skills expected of them. Additionally, only $31 \%$ of eighth graders scored at or above the "proficient" level, defined as solid academic performance and competency over challenging subject matter. Information on 12th-grade students is even more alarming, with $36 \%$ of 12 th-graders scoring below the basic level and only $24 \%$ at or above the proficient level (Lee, Grigg, \& Dion, 2007). These results suggest that secondary students are not attaining an acceptable level of mastery of the mathematics curriculum.

Mathematics achievement of secondary students with disabilities deserves even closer attention. The Nation's Report Card indicated that, although some improvements in mathematics achievement have been documented for students with disabilities from 1996 to 2007 , little progress has been made to close the gap between the achievement scores of

Paula Maccini and Tricia Strickland are affiliated with the University of Maryland, College Park. Joseph Calvin Gagnon is affiliated with the University of Florida, Gainesville, and Kimber Malmgren with the University of Wisconsin, Madison. 
students with disabilities and those of their nondisabled peers. Specifically, in 1996, among students performing below the basic level, a 46.5\% gap existed between the students with disabilities and those without. Similarly, in 2007, $41 \%$ more students with disabilities scored below the basic level of performance than students without disabilities. The most recent NAEP reports $66 \%$ of eighth-grade students with disabilities performed below the basic level on the NAEP in mathematics, in contrast to $25 \%$ for students without disabilities (Lee et al., 2007). Additionally, $83 \%$ of 12th-graders with disabilities scored below the basic level compared to only $36 \%$ of students without disabilities performing below the basic level (Lee et al., 2005). Poor youth performance is also noted at the state level. In terms of highstakes assessments in math, the state of Maryland, which requires all students to pass an algebra/data analysis assessment to earn a diploma, found that $63.5 \%$ of all students taking this exam passed; however, only $28.6 \%$ of students with disabilities passed (Maryland State Department of Education, 2008).

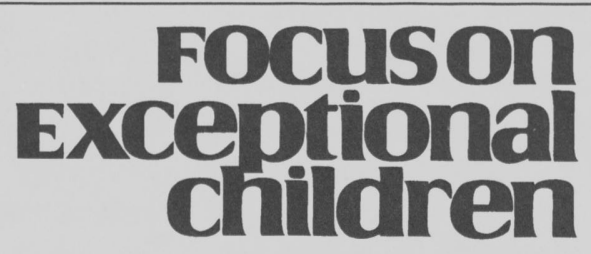

ISSN 0015-511X FOCUS ON EXCEPTIONAL CHILDREN (USPS 203-360) is published monthly except June, July, and August as a service to teachers, special educators, curriculum specialists, administrators, and those concerned with the special education of exceptional children. This publication is annotated and indexed by the ERIC Clearinghouse on Handicapped and Gifted Children for publication in the monthly Current Index to Journals in Education (CIJE) and the quarterly index, Exceptional Children Education Resources (ECER). The full text of Focus on Exceptional Children is also available in the electronic versions of the Education Index. It is also available in microfilm from Serials Acquisitions, National Archive Publishing Company, P.O. Box 998, Ann Arbor, MI 48106-0998. Subscription rates: individual, \$42 per year; institutions, \$56 per year. Copyright @ $\odot$ 2008, Love Publishing Company. All rights reserved. Reproduction in whole or part without written permission is prohibited. Printed in the United States of America. Periodical postage is paid at Denver, Colorado. POSTMASTER: Send address changes to:

Love Publishing Company

Executive and Editorial Office P.O. Box 22353

Denver, Colorado 80222

Telephone (303) 221-7333

\section{EDITORIAL BOARD}

Lisa Dieker

University of Central Florida
Paula Maccini University of Maryland

Marleen Pugach

University of Wisconsin-Milwaukee

Carrie E. Watterson Editor
Stanley F. Love

Publisher
Low performance of students in mathematics has been a concern for decades. In 1983, the National Commission on Excellence in Education released a report entitled A Nation at Risk, which implied that U.S. schools were performing poorly in comparison to other industrialized nations and that the United States was at risk for losing its global standing (Amrein \& Berliner, 2002). This report caused a national concern that initiated educational reform in all content areas, including mathematics. Professional organizations and legislative mandates called for more rigorous mathematics standards incorporating problem-solving and reasoning skills for all learners. In 1989, the National Council of Teachers of Mathematics (NCTM) first published the Curriculum and Evaluation Standards for School Mathematics, which emphasized conceptual understanding and real-world problem solving and deemphasized rote learning. The NCTM Standards set forth five goals to guide math education. These goals were that students should (a) value mathematics, (b) become confident in their own mathematics ability, (c) become mathematical problem solvers, (d) learn to communicate mathematically, and (e) learn to reason mathematically.

In keeping with the five overall goals, the standards were revised in 2000 to become the Principles and Standards for School Mathematics, which reflect the needs of an increasingly technological society and a belief in the importance of mathematics for all students, including students with learning needs. The Content Standards describe the content that all students should learn from pre-kindergarten through 12th grade (i.e., number and operations, algebra, geometry, measurement, data analysis, and probability). The Process Standards describe ways students across all grade bands should acquire and apply content knowledge in terms of problem solving, reasoning and proof, communication, connections, real-life situations, and representation (NCTM, 2000).

The NCTM also states six general principles of mathematics which describe the characteristics of high-quality mathematics education: (a) equity for all students to meet high expectations and excel in mathematics; (b) a curriculum that integrates all aspects of mathematics in a meaningful manner; (c) effective teaching practices that reflect a deep understanding of math and how students learn mathematics; (d) student learning to promote conceptual understanding of mathematics, in addition to factual and procedural understanding; (e) assessment that supports the learning of mathematics and guides instructional decisions; and (f) the use of technology to enhance student learning of mathematics. All states but one have aligned their mathematics curriculum standards to the NCTM Standards (Woodward, 2004). Despite this effort, students with disabilities continue to perform below their nondisabled peers.

In addition to the higher math standards set forth by NCTM, the Individuals with Disabilities Education Act 
(IDEA, 2004) and the No Child Left Behind Act (NCLB, 2002) require that all students, including students with disabilities, have access to grade-appropriate curricula. However, to promote student access to the general education curriculum, teacher use of empirically validated instructional practices within all educational settings is crucial.

\section{MATHEMATICS ACROSS SCHOOL SETTINGS}

As espoused within the equity principle of the revised NCTM (2000), all students should have access to a quality math education and corresponding support to help them be successful. Further, providing an age-appropriate quality math education to all students is critical, regardless of the setting in which the students are educated (Gagnon \& Bottge, 2006). Many of our most volatile youth are served in exclusionary school settings. Gagnon and Bottge identified several of these alternative school settings, including "(a) therapeutic day treatment schools, (b) therapeutic residential schools, (c) juvenile correctional schools for detained youth, and (d) juvenile correctional schools for committed youth" (p. 39). Juvenile correctional schools for committed youth (JC) are, perhaps, the educational setting where access to the general education curriculum via research-based instruction is the most needed (Gagnon \& Bottge, 2007; Gagnon \& Mayer, 2004; Maccini, Gagnon, Mulcahy, \& Leone, 2006). Complications exist within JC schools that may present barriers to both access to the general education curriculum and teacher ability to implement appropriate instructional strategies. For example, the proportion of students with special needs is approximately $40 \%$ of the student population as compared to $11 \%$ of the population classified with a disability in schools nationally (Gagnon, Barber, \& Van Loan, 2008; Quinn, Rutherford, Leone, Osher, \& Poirer, 2005; U.S. Department of Education, 2004). Students with a learning disability (LD) or an emotional behavioral disability (EBD) are each estimated to be $30-50 \%$ of the total population of students with disabilities being served in JC schools (Gagnon et al., 2008; Quinn et al., 2005).

The high percentage of students with disabilities in JC schools has important implications for instruction. For example, Cawley and Miller (1989) reported that secondary students with LD typically perform at approximately a fifthgrade level on math tasks. Also, according to Bryant, Kim, Hartman, and Bryant (2006), areas of math difficulty include (a) memory problems, such as retrieving math facts (Garnett \& Fleischner, 1983) and remembering and using multiple steps to solve problems (Bley \& Thornton, 1995; Bryant, Bryant, \& Hammill, 1990; Parmar, Cawley, \& Frazita, 1996); (b) language processing difficulties involving receptive language (e.g., comprehending math vocabulary and math word problems) and expressive language (e.g., justifying the reasonableness of an answer); and (c) cognitive developmental difficulties with processing math facts, procedural strategies and rules, and math concepts. Additionally, students with EBD typically have difficulty focusing attention, metacognitive deficits such as monitoring and evaluating performance, and trouble retrieving learned information (Mulcahy \& Gagnon, 2007).

Information concerning the use of effective mathematics instruction specifically within JC schools is severely limited. However, Maccini and colleagues (2006) found that few effective teaching practices such as use of technology or computers, real-world activities, graduated instructional sequences, and grouping for instruction were being employed in JC schools. Additionally, Coffey and Gemignani (1994) reported that instruction within juvenile correctional facilities commonly consists solely of drill and practice, rather than the conceptually based instruction advocated by experts and NCTM.

Clearly, in all educational settings youth with disabilities, particularly those with LD and EBD, frequently have difficulties in mathematics. For teachers to provide students with access to the grade-level curriculum, a reliance on empirically validated instruction is essential. In this paper, we report on teachers' use of empirically validated math practices within JC schools. We highlight the effective instructional approaches that span all educational settings and discuss methods of addressing some of the unique difficulties within a JC school setting. While the context for these approaches and methods is JC schools, the recommendations and examples are applicable to youth in educational settings from the most inclusive to the most restrictive.

Specifically, our purpose is to (a) share the results of a national survey on the extent to which secondary special education teachers in JC schools provide research-based instruction; (b) offer implications and recommendations for teaching math to students with LD and EBD using researchbased mathematics instruction across educational settings; (c) highlight adaptations possible for JC schools; and (d) provide lesson examples that can be applied across settings.

\section{NATIONAL STUDY OF JC SCHOOLS}

To address the first purpose, we will discuss a national mail and online survey of JC schools for committed youth. The survey focused on math teachers within these schools (see Maccini \& Gagnon, 2008). Survey items included questions about the characteristics of the teacher, students, and school, as well as use of math instructional practices identified from a comprehensive review of the literature (Maccini et al., 2006). Through this review of research, we provide implications, recommendations, and examples of researchbased mathematics instructional approaches that apply 
across school settings. Moreover, specific JC school characteristics supply the basis for additional adaptations for JC schools.

The majority of teachers responding to the survey of JC schools held graduate degrees, reported teaching math and special education an average of 10 years, and noted their current teaching position as either a full-time self-contained teacher or a resource room teacher. The majority of teachers stated they were currently teaching general math or basic skills for high school, middle school math, prealgebra, algebra, and geometry. Results indicated that teachers generally have the necessary education and experience to provide appropriate mathematics instruction. Also, the courses taught are consistent with courses taught by teachers of students with disabilities in public schools (Maccini \& Gagnon, 2002).

In the study, teachers reported the frequency of use of math instructional practices as well as reasons for not using certain practices. The instructional practices, organized into six approaches, are consistent with those identified as effective for youth with LD and EBD throughout the range of educational settings (Maccini et al., 2006; Maccini, Mulcahy, \&
Wilson, 2007). In what follows, we describe the six practices, applications to the continuum of educational placements, and specific JC school considerations.

We also provide three lesson plans that illustrate the integration of recommended practices into a variety of classrooms (Figure 1 presents a matrix of the integration of the instructional practices per lesson). For example, the lessons (see Figures 4, 5, and 6) address multiplying two binomials across three stages (concrete, semi-concrete, abstract) that will be discussed in the section on the graduated instructional sequence. At the concrete level, students use algebra tiles as they determine the product of the two expressions. At the semi-concrete level, students draw pictures of the tiles and work with virtual manipulatives. In the final lesson, students progress to the use of abstract symbols only. Each lesson also incorporates five major steps of the explicit instructional cycle (Hudson \& Miller, 2006). Additionally, the lesson plans offer suggestions for remediation and extension.

Throughout the sample lessons, the teacher encourages active engagement of all students, which is especially important for students with LD and EBD who are often passive learners. Additionally, student participation allows the

\begin{tabular}{|c|c|c|c|}
\hline & $\begin{array}{c}\text { Lesson } 1 \\
\text { (Concrete) }\end{array}$ & $\begin{array}{c}\text { Lesson } 2 \\
\text { (Semi-Concrete) }\end{array}$ & $\begin{array}{l}\text { Lesson } 3 \\
\text { (Abstract) }\end{array}$ \\
\hline $\begin{array}{l}\text { Direct } \\
\text { Instruction }\end{array}$ & $\begin{array}{l}\text { - Curriculum-based } \\
\text { assessment } \\
\text { - Advanced organizer } \\
\text { - Teacher } \\
\text { demonstration } \\
\text { - Guided practice } \\
\text { - Independent practice }\end{array}$ & $\begin{array}{l}\text { - Curriculum-based } \\
\text { assessment } \\
\text { - Advanced organizer } \\
\text { - Teacher } \\
\text { demonstration } \\
\text { - Guided practice } \\
\text { - Independent practice }\end{array}$ & $\begin{array}{l}\text { - Curriculum-based } \\
\text { assessment } \\
\text { - Advanced organizer } \\
\text { - Teacher } \\
\text { demonstration } \\
\text { - Guided practice } \\
\text { - Independent practice }\end{array}$ \\
\hline $\begin{array}{l}\text { Strategy } \\
\text { Instruction }\end{array}$ & $\begin{array}{l}\text { - STAR strategy with } \\
\text { cue card }\end{array}$ & $\begin{array}{l}\text { STAR strategy with } \\
\text { cue card }\end{array}$ & $\begin{array}{l}\text { - STAR strategy with } \\
\text { cue card } \\
\text { - Mnemonic-FOIL } \\
\text { - Cue card for } \\
\text { graphing calculator }\end{array}$ \\
\hline $\begin{array}{l}\text { Real-World } \\
\text { Activities }\end{array}$ & $\begin{array}{l}\text { Problems in real- } \\
\text { world context }\end{array}$ & $\begin{array}{l}\text { Problems in real- } \\
\text { world context }\end{array}$ & $\begin{array}{l}\text { Problems in real- } \\
\text { world context }\end{array}$ \\
\hline Technology & - Virtual manipulatives & $\begin{array}{l}\text { Virtual } \\
\text { manipulatives }\end{array}$ & $\begin{array}{l}\text { - Virtual } \\
\text { manipulatives } \\
\text { - Graphing calculators } \\
\text { - Computer websites }\end{array}$ \\
\hline $\begin{array}{l}\text { Graduated } \\
\text { Instructional } \\
\text { Sequence }\end{array}$ & $\begin{array}{l}\text { - Algebra tiles } \\
\text { - Virtual manipulatives }\end{array}$ & $\begin{array}{l}\text { - Algebra tiles } \\
\text { - Drawings } \\
\text { - Virtual } \\
\text { manipulatives } \\
\end{array}$ & $\begin{array}{l}\text { - Drawings } \\
\text { - Algorithm with } \\
\text { abstract numbers } \\
\text { and symbols }\end{array}$ \\
\hline $\begin{array}{l}\text { Grouping } \\
\text { for } \\
\text { Instruction } \\
\end{array}$ & $\begin{array}{l}\text { - Remediation and } \\
\text { extension groups }\end{array}$ & $\begin{array}{l}\text { - Remediation and } \\
\text { extension groups }\end{array}$ & $\begin{array}{l}\text { - Remediation and } \\
\text { extension groups }\end{array}$ \\
\hline
\end{tabular}


teacher to continually check for student understanding. Space limitations permit inclusion of only one problem in the lesson plans for teacher modeling and for guided practice. In reality, students will require more problems, particularly in guided practice. Hudson and Miller (2006) suggested four levels of support (high, medium, low, and no prompts) during guided practice. For example, the concrete lesson (see Figure 4) represents providing a high to medium level of support during guided practice as students are first introduced to the use of algebra tiles to represent multiplying binomial expressions. The semi-concrete lesson (see Figure 5) represents medium to low levels of support, provided during guided practice as students extend their knowledge of the representations to pictorial displays. The abstract lesson (see Figure 6) represents a medium level of support as students move to more abstract representations with the use of a new mnemonic. Students should have adequate support for progressing to solving problems without any prompts before they advance to independent work.

All three lessons provide contextualized word problems that students must solve through the multiplication of binomials. Students use a mnemonic strategy, STAR, to gather the necessary information from the word problems and translate the words into binomial expressions. With the repeated prompting of the STAR strategy, students then proceed to solve the problem by multiplying these expressions.

\section{RECOMMENDED PRACTICES}

As noted, teachers reported their use of effective math practices in six areas: (a) direct/explicit instruction; (b) strategy instruction; (c) real-world activities and use of technology; (d) graduated instructional sequence; (e) grouping for instruction; and (f) other instructional adaptations. We first define each category and discuss the research support. We then note the frequency with which teachers reported using the practices and the reasons some teachers gave for not using them. Finally, we offer recommendations for practice through examples and resources based on the survey data and the extant literature.

\section{Direct/Explicit Instruction}

Definition. Direct instruction (di) refers to a systematic approach to teaching a new skill or concept in which the teacher continuously checks for student understanding and engages all students in the lesson (Rosenshine \& Stevens, 1986). The steps of di include a review of prerequisite skills, teacher demonstration and modeling of the skill, guided practice, independent practice, and review. (See Figure 2 for an explanation of each step.) Hudson and Miller (2006) expanded the general teaching sequence and included curriculum-based instruction and planning for instruction (see
Figure 2). Curriculum-based instruction helps the teacher to place students in the curriculum based on evaluation of assessment data and to monitor their progress over time. Planning for instruction includes the use of data-based decision making and instructional alignment (i.e., matching learner characteristics to the lesson and aligning the content of the lesson components with one another).

Use of the di approach has proven effective for teaching math to middle school and high school students with LD within general education and resource room classrooms (Hudson \& Miller, 2006; Maccini \& Hughes, 1997; Maccini et al., 2007) and is also highly recommended within JC schools (Maccini et al., 2006). Two studies (Ozaki, Williams, \& McLaughlin, 1996; Scarlato \& Burr, 2002) included positive learning gains for teaching middle school students with LD in public school settings. For example, Ozaki and colleagues (1996) determined that teaching students a copy/cover/compare drill-and-practice procedure using di was successful for teaching a sixth-grade student with LD to master multiplication facts. The copy/cover/ compare sequence was embedded in the following instructional procedures: (a) look at the completed math fact; (b) read the problem aloud and COPY the answer; (c) COVER the problem; (d) read the problem aloud and write from memory; and (e) COMPARE the answer to the original modeled problem.

Across a variety of school settings, researchers (Hudson \& Miller, 2006; Maccini et al., 2006) recommend using di daily or at least once a week. Teachers in JC schools reported using modeling, guided practice, independent practice, and feedback on either a daily or weekly basis (see Figure 3). The teachers also noted using advance organizers, scaffolded instruction, and cumulative reviews sometimes or never. The infrequent use of key components of di are in contrast to researcher assertions that these parts of di should be used frequently in school settings that range from the most inclusive to exclusive (Hudson \& Miller, 2006; Ozaki et al., 1996; Scarlato \& Burr, 2002).

Among teachers who reported not using specific di variables, the most common reason given was the need for more training, followed by reports of beliefs that the strategies do not meet the academic needs of their students, lack of materials and resources, and the approach not matching the teacher's views on teaching. Interestingly, although the lack of materials was the most frequent concern expressed, the di approach requires few materials for implementation. The concerns regarding need for training and lack of teacher understanding may stem from the view that extensive materials are needed for implementation, and the JC teacher concern with a lack of materials for di may actually be part of a more general concern regarding inadequate materials. In fact, general and special education teachers in regular public schools also 


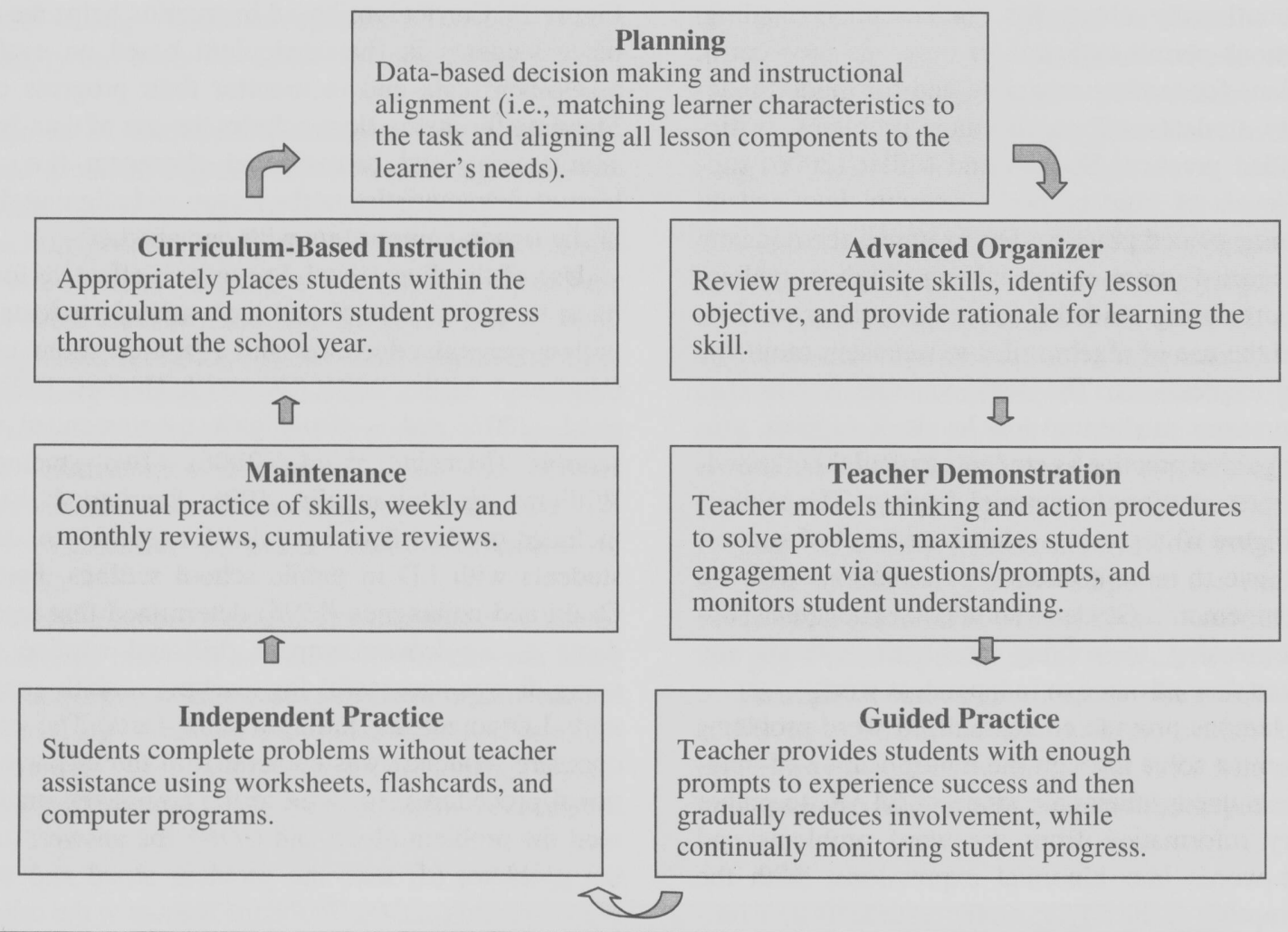

Source: Hudson and Miller, 2006

\section{FIGURE 2 \\ Explicit instruction sequence}

reported lack of appropriate materials to be a serious barrier to their implementation of effective mathematics instruction (Maccini \& Gagnon, 2002).

To clarify how to effectively implement di we provide suggestions, as well as three lesson plans that incorporate di with additional adaptations and effective practices to help meet the needs of diverse learners in all classrooms. The examples also contain enrichment and remediation ideas, suggestions for teacher wording, and ways to help students use a cue card that lists general problem-solving strategy steps.

\section{Implications for Practice}

As the di approach is recommended for secondary youth with both LD and EBD, we describe approaches to implementation that span all educational settings in which these students learn. In addition, we address some of the unique considerations for teachers in more exclusionary settings, such as JC schools. Like teachers in other classrooms, teachers in JC schools are faced with students who are academically diverse. Hudson and Miller (2006) recommend varying the lesson plan format to address the needs of multiple groups within a classroom using a multiple groups/complete cycle format. With this approach, the teacher carefully plans for a balance across instructional groups using teacherdirected and independent activities. For example, the teacher may provide guided practice to one group but assign a more advanced group to work on maintenance of previously learned skills or an extension activity. Sample lesson plans that contain components of explicit instruction are included with ideas for differentiating instruction through extensions and remediation within an academically diverse classroom (see Figures 4, 5, and 6).

Providing students with an advanced organizer was the variable most often omitted from the teaching process. Scarlato and Burr (2002) recommended assessing and systematically teaching prerequisite skills daily to build a foundation for academic gains. Scaffolded instruction is an equally important di component and can be easily incorporated with daily guided practice. The instructional practice initially engages the learners in guided practice with the teacher offering prompts and remodeling as needed. As the students become more proficient and confident in their ability to complete the task, the teacher gives fewer and fewer prompts and, gradually, the responsibility of completing the task shifts from the teacher to the student (Hudson \& Miller, 2006). At the point where students are ready to accept complete responsibility for completing tasks, 


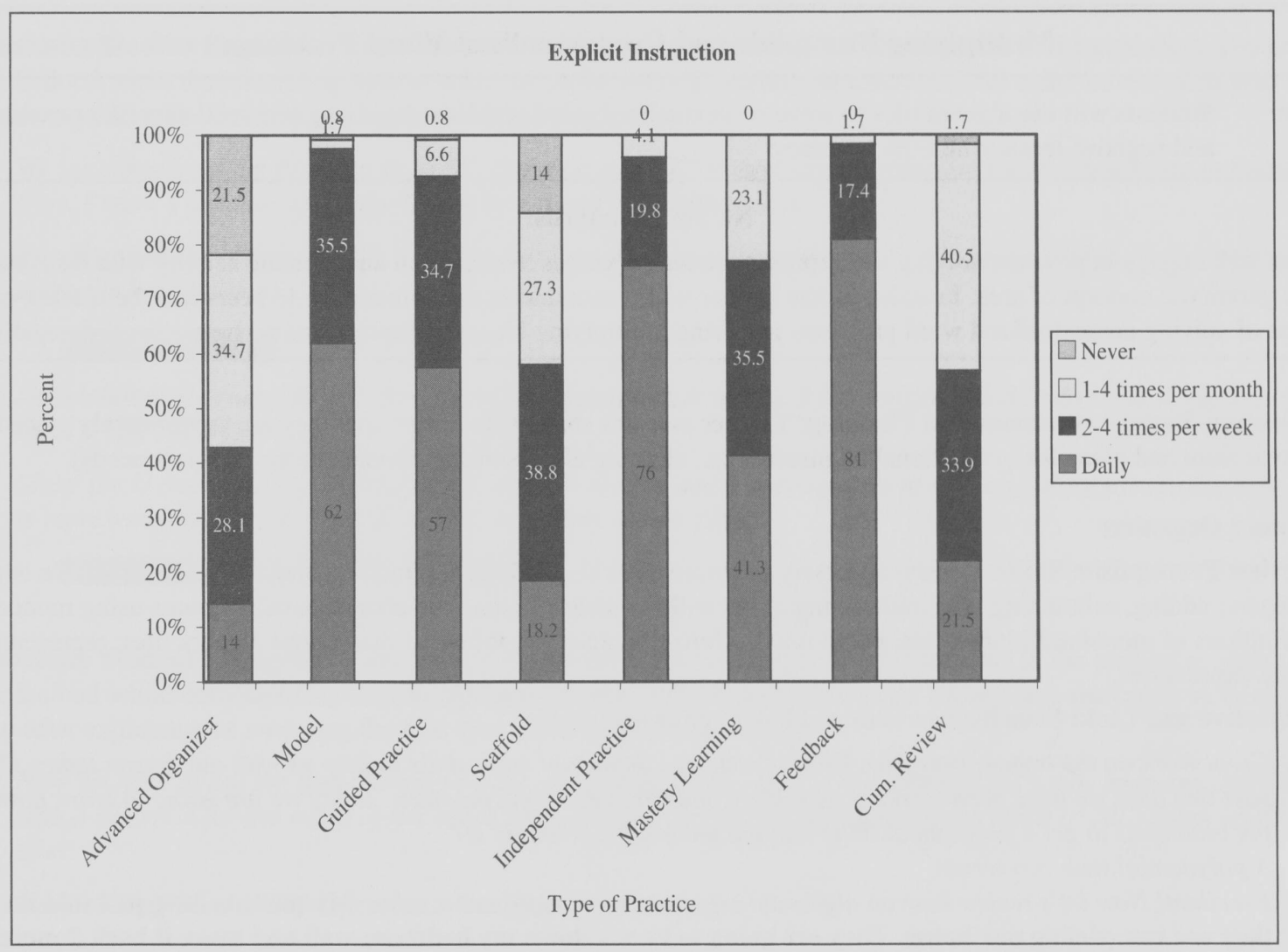

FIGURE 3

Percentage of use of variables of explicit instruction reported

they continue with independent practice. Similarly, cumulative reviews are an important component of instruction, particularly for students with LD who typically have difficulty retaining information. Teachers can incorporate cumulative reviews into the curriculum daily as part of independent practice. Cumulative review can also serve as a curriculum-based assessment at the beginning of a new topic to ensure that students possess the necessary prerequisite skills for learning new skills and concepts.

\section{EXPLICIT INSTRUCTION RESOURCES}

\section{Suggested Readings:}

$\checkmark$ Gagnon, J. C., \& Maccini, P. (2005). Direct instruction in middle school mathematics for students with learning disabilities. Washington, DC: American Institute for Research. Retrieved March 31, 2008, from http://www.k8accesscenter.org/training _resources/directinstruction math.asp

$\checkmark$ Hudson, P. \& Miller, S.P. (2006). Designing and implementing mathematics instruction for students with diverse learning needs. Boston: Pearson Education, Inc.

\section{Strategy Instruction}

\section{Definition}

A strategy is a plan for addressing a problem situation and includes following a sequence of actions and guidelines to help make effective decisions during the problem-solving process (Ellis \& Lenz, 1996). Common elements of effective strategies for students with LD are (a) a memory device, such as a first-letter mnemonic to aid in remembering the problem-solving steps; (b) familiar words or phrases that begin with an action verb (e.g., "Read the problem") to prompt students to use the strategy; and (c) sequenced steps to help students remember and recall the process.

Use of strategy instruction (SI) has been proven to be effective in settings that range from general education to JC schools (Maccini et al., 2006). Specifically, SI involving schema-based instruction (Jitendra, DiPipi, \& Perron-Jones, 2002; Jitendra, Hoff, \& Beck, 1999; Xin, Jitendra, \& Deatline-Buchman, 2005) and mnemonic strategy instruction (Manalo, Bunnell, \& Stillman, 2000; Test \& Ellis, 2005) is effective for teaching problem solving, decimal numbers, 


\section{Multiplying Binomials and Contextualized Word Problems}

Objective: Students will use algebra tiles to solve contextualized word problems involving binomial expressions with positive and negative terms with $80 \%$ accuracy.

\section{NCTM Standards:}

The learner will engage in problem-solving and representational processes to engage in an algebraic activity with distributed practice in the geometric concept of area. In addition, the learner will communicate mathematically to peers and the teacher concerning the process of solving contextualized word problems involving multiplying binomial expressions with positive and negative terms.

I. Curriculum-Based Assessment and Planning: Teacher assesses students to ensure that they are appropriately placed within the curriculum and plans for instructional alignment (i.e., aligning all lesson components to the learner's needs).

\section{Advanced Organizer}

a. Review Prerequisite Skills: Review necessary prerequisite skills: adding, subtracting, and multiplying positive and negative integers; adding, subtracting, and multiplying terms with variables; finding the area of parallelograms using monomials; definitions of monomials, binomials, polynomials; Zero Principle; the values of the various algebra tiles; representing algebraic expressions.

b. Objective and Link: State the new skill and link to prior knowledge.

T: Great work on the review, everyone. We just reviewed important math skills to help us with our lesson today. Over the past two days we have been working on adding and subtracting polynomials. Today we are going to learn how to multiply binomials to get a polynomial. Who can tell me what a binomial is?

S: A polynomial with two terms.

T: Excellent! Now let's review how an algebraic expression can represent a value. My parents have just told me that they are remodeling our house. They are going to knock down my bedroom wall and move it back $\mathbf{2}$ meters, therefore, extending the length of my bedroom. How can I represent the length of my bedroom using an expression?

S: $x+2$

T: You got it! The length of my bedroom has just been extended by 2 meters; therefore, the length of my bedroom now is $x$ +2 meters long.

c. Rationale: Develop rationale for multiplying binomials.

T: Excellent! Multiplying binomials is a building block for solving more advanced algebra problems. These skills are assessed on the state exit exam as well as on college entrance exams. Additionally, this skill is used in many real-world situations, such as determining the area when planning for room or building renovations.

\section{Demonstration}

a. Model Thinking and Action: Think aloud while explaining how to represent and solve the problem using the algebra tiles and referring to the STAR cue card.

T: Our first problem is:

Jill's house is being renovated and her bedroom will be enlarged. Currently, her room is shaped like a square. After the renovations, the length of Jill's bedroom will be 3 feet longer and the width will be 2 feet longer. Write an expression to represent the new dimensions of Jill's bedroom and the polynomial expression for the area of Jill's new bedroom.

I'm going to use our word problem strategy, STAR. The first step, S: Search the word problem, means I need to read the problem carefully and search for what the problem is asking for me to find. Now, let me get some information from our problem. What do I know? (Teacher rereads problem to class.) Extend length by $3 \mathrm{ft}$ and the width by $2 \mathrm{ft}$. I need to find the length of Jill's bedroom. 
b. Maximize Student Engagement and Monitor Student Understanding: Involve students in the process as you continue to think aloud while demonstrating how to solve the problems (e.g., calling on a student(s) to state the next step after explaining or modeling the first step, group/choral responding).

T: We just completed the first step in STAR. Our next step "T," means we will translate the problem using our manipulatives. I know I need to extend the length by $3 \mathrm{ft}$ and the width by $2 \mathrm{ft}$.

I need to find the length of Jill's bedroom, but I do not know the number so I will use a variable, "x," as represented using the long black tile.

Jill's bedroom is currently " $x$ " feet and after renovations, it will be 3 feet longer which I can show using 3 grey square tiles.

Since she is extending her bedroom by 3 feet, l'll need to add 3 grey squares to our long black tile. So my first binomial is represented by one long black tile and three grey square tiles.

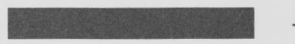

c. Maximize Student Engagement and Monitor Student Understanding: Involve students in the process as you continue to think aloud while demonstrating how to represent the problem using the tiles (e.g., calling on a student(s) to state the next step after explaining or modeling the first step, group/choral responding).

T: Now we need to use the tiles to represent the polynomial expression for the width of Jill's new bedroom. Let's come up with a binomial for the width of her room. How can we use the tiles to represent the width of Jill's room now? Everyone?

S: Use one long black tile to represent $x$ feet long.

T: Yes! We will use one long black tile to represent $x$ feet long because Jill's room is currently in the shape of a square, which has all sides of equal length. Jill's room will be 2 feet longer after renovations. What tiles will we use to represent it?

S: Two grey square tiles.

T: Great job finding information from the word problem! The width of Jill's room can be represented as follows:

T: Good work, class! We have just thought of an expression to represent the new length and width of Jill's bedroom.

T: Jill's bedroom will be a rectangle because the length and the width are not of equal size. Who can tell me how we find the area of a rectangle?

S: Multiply the length times the width.

T: We will now multiply these two binomials using our algebra tiles to help us to visualize the problem. I will demonstrate how to do this by using algebra tiles on an overhead projector.

T: First, I will place my $x$-bar and my three constants on the top of my corner piece. I will place my tiles that represent " $x+2$ " on the side of my corner piece. Now I will distribute my top $x$-bar to all the tiles in the side of my corner piece:

- Remember, $x$-bar times an $x$-bar equals $x^{2} . I$ know this because my $x^{2}$ tile is a large square that fits perfectly between the two $x$-bars.

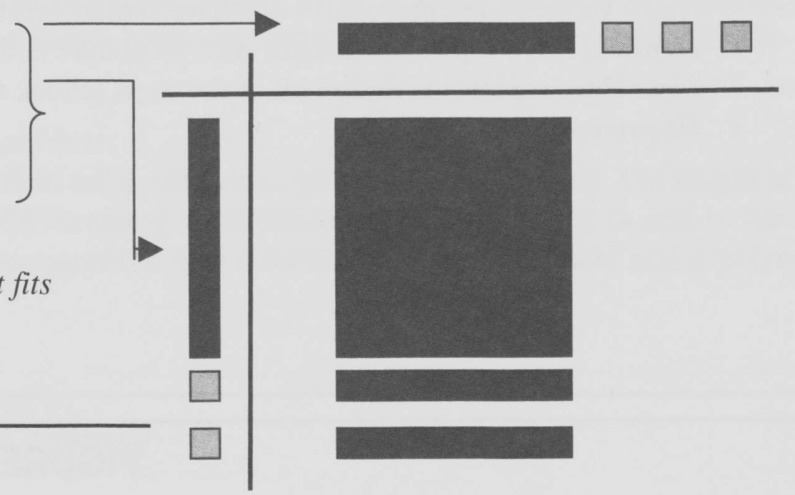


- Next, $x$-bar times a constant equals an $x$-bar.

I know this because this fits perfectly into the space on my corner piece. Show me this with your tiles (walk around to pairs and monitor student responses).

Second, I will multiply the first constant on the top of our corner piece with all the tiles on the side of our grid. Remember, a constant times a constant will equal a constant.

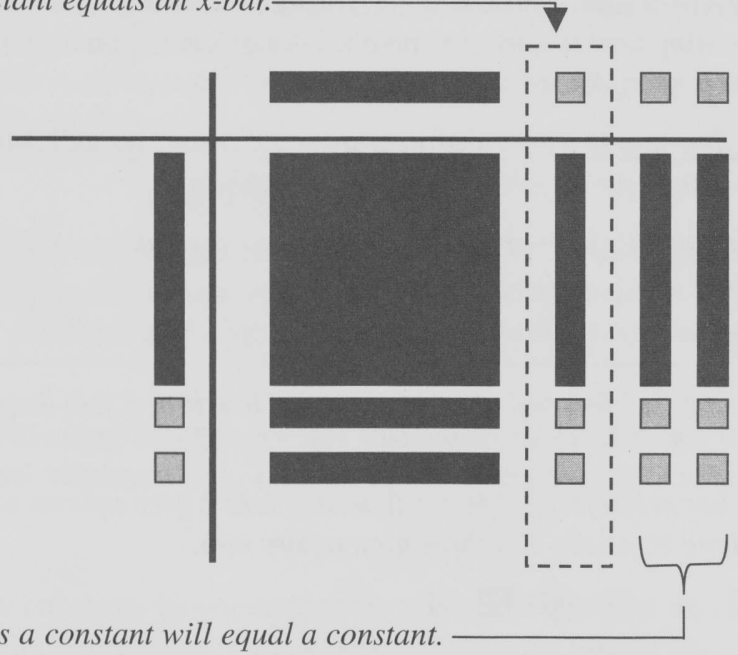
Show me this with your tiles (monitor student responses).

Help me out with the third step and last step (have students demonstrate distributing the last two constants on the top to all of the tiles on the side).

Give me a thumbs-up if you agree.

T: OK, our third step in STAR is to Answer the problem. (Review cue card of STAR steps.) Now let's look at our tiles to determine the answer to our problem. With your fingers, show me how many $x$ squares we have in the solution?

S: Students hold up 1 finger.

T: That's right! What about $x$ bars?

S: Students hold up 5 fingers.

T: How many constants?

S: Students hold up 6 fingers.

T: Great answers! That means our answer is $x^{2}+5 x+6 . O K$, what is our last step in STAR? That's right, review the answer. (Read the word problem and review the answer with the class.) The polynomial expression that represents the area of Jill's bedroom after renovations is $x^{2}+5 x+6$. Let's do another problem together! You and your partner will share a set of algebra tiles and work together to solve the next problem.

\section{Guided Practice}

a. Provide guidance as students perform 3 or 4 more problems with use of the STAR cue card and algebra tiles.

b. Reduce your level of support as students assume more responsibility for the learning. For example:

- High: Verbalize the procedures and have students restate and/or apply.

- Medium: Have students verbalize each procedure and apply.

- Low: Have students verbalize all of the steps (chunk together) and apply.

- No prompts. 
T: Our next problem is:

Our school has just received permission to use some of the field adjacent to our sports field. Currently, the length of our school's field is 2 meters longer than the width. We will be receiving an additional 2 meters of field to add to the length, but we will be losing 3 meters from our width. Determine an expression to represent the new dimensions of our new field and a polynomial expression for the area of our new field. (Have students use their STAR cue card and follow the first step, Search the word problem. They are to note the facts and what they need to find.)

T: Very impressive! You remembered to use negative constants, because we are subtracting 3 meters

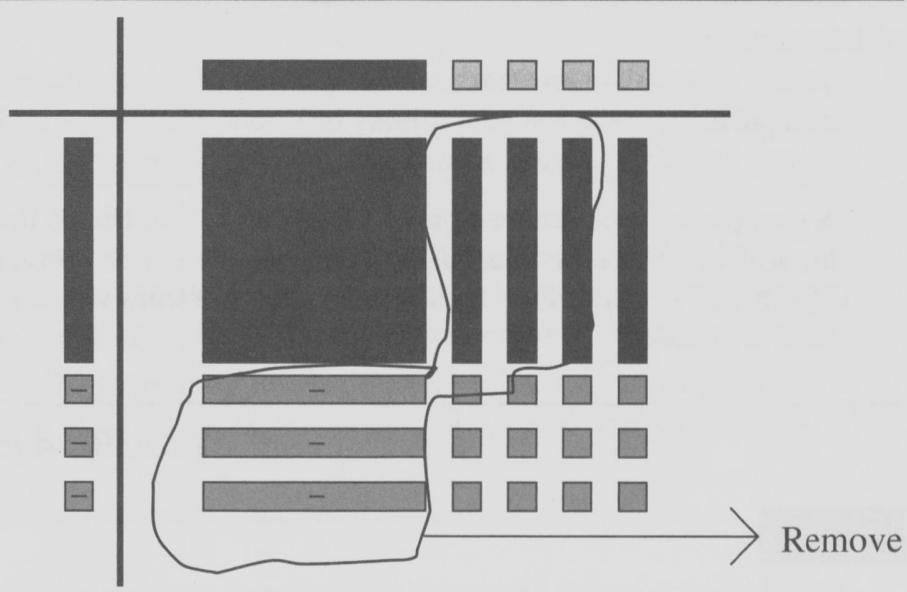
from the width of our field. Now distribute each top tile to all of the side tiles. (Teacher walks around the room providing corrective feedback and remodeling as needed.)

T: Great work, everyone! Your tiles should look like mine on the overhead.

T: Now, since we have both positive and negative integers, we need to remember our Zero Principle. Think about the Zero Principle, explain to your partner, and be prepared to explain to the class.

S: A positive integer and its opposite negative integer equal zero.

T: Great remembering! Since we have three negative $x$-bars, how many positive $x$-bars will cancel out because of the Zero Principle. Everyone hold up that number of fingers.

S: Hold up 3 fingers.

T: Excellent! You are now ready to tell your partner the final answer to our problem. What is the polynomial that represents the area of our new field? (Prompt students to review the next step of the cue card to answer the problem.)

T: Next what should we do?

S: R: Review the answer.

T: Have students read the word problem and call on students to justify the reasonableness of their answer.

V. Independent Practice

a. Provide additional contextualized problems for students to complete independently.

b. Monitor student work and address misconceptions/errors.

c. Review the accuracy of student responses.

\section{Remediation}

Students work with the teacher to solve additional problems using algebra tiles. The teacher will model the following problem. Sam's house is being renovated, and her bedroom will change in size and shape. Currently, her room is shaped like a square. After the renovations, the length of Sam's bedroom will be $\mathbf{5}$ feet longer, but the width will be $\mathbf{4}$ feet shorter. Represent an expression using the tiles for the dimensions of Sam's bedroom and the polynomial expression for the area of the new bedroom.

The teacher will then engage the students in a guided practice problem.

Our school has just received permission to use some of the field adjacent to our sports field. Currently, the length of our school's field is 1 meter longer than the width. We will be receiving an additional 3 meters of field to add to the length and 2 meters to our width. Write an expression to represent the new dimensions of our new field and a polynomial expression for the area of our new field. 


\section{Extension}

Students work with less teacher assistance in pairs or small groups to represent and solve the following problem using virtual manipulatives at the National Library of Virtual Manipulatives: http://nlvm.usu.edu/en/nav/frames _asid_189_g_4_t_2.html?open=activities\&from=cate gory_g_4_t_2.html

A group of school children play kickball on a field that is lined with trees at one end. The length of this field is twice the width. After removing the line of trees, the length increased by 4 meters. Using virtual manipulatives, represent the length and width of the kickball field after the trees were removed. Then determine the area of the field using a polynomial expression.

FIGURE 4 (Continued)

\section{Multiplying Binomials and Contextualized Word Problems}

Objective: Students will use pictorial displays to solve contextualized word problems involving binomial expressions with positive and negative terms with $80 \%$ accuracy.

\section{NCTM Standards:}

The learner will engage in problem-solving and representational processes to engage in an algebraic activity with distributed practice in the geometric concept of area. In addition, the learner will communicate mathematically to peers and the teacher concerning the process of solving contextualized word problems involving multiplying binomial expressions with positive and negative terms.

I. Curriculum-Based Assessment and Planning: Teacher assesses students to ensure that they are appropriately placed within the curriculum and plans for instructional alignment (i.e., aligning all lesson components to the learner's needs).

\section{Advanced Organizer}

a. Review Prerequisite Skills: Review necessary prerequisite skills as identified in the concrete phase and review the use of the algebra tiles to represent and solve contextualized problems. For example:

T: For today's warm-up problem, we will use the algebra tiles to solve the problem:

Miriam's house is being renovated, and her bedroom will be enlarged. Currently, her room is shaped like a square. After the renovations, the length of Miriam's bedroom will be 2 feet longer and the width will be 1 foot longer. Write an expression to represent the new dimensions of Miriam's bedroom and the polynomial expression for the area of Miriam's new bedroom.

b. Objective and Link. State the new skill and link to prior knowledge.

T: Yesterday we used the algebra tiles to help us to multiply binomials to get a polynomial. Today, we are going to use pictures to represent the tiles to solve problems.

c. Rationale: Develop rationale for multiplying binomials.

T: Great job on your warm-up problem! Now we are going to put our tiles away, but I want you to remember the shape and size for each tile and what they represent, because for today's lesson we are going to just draw our tiles. We can't always use tiles, for example when we take the SATs, but we can draw the tiles as a way of solving the problem. We can draw pictures of the tiles as another tool to help us to visualize the information in the word problem 


\section{Demonstration}

a. Model Thinking and Action: Think aloud while explaining how to represent and solve the problem using pictures of the algebra tiles and referring to the STAR cue card.

T: Review the STAR strategy steps with the class—both individual and group responses (e.g., The S stands for what?). I'm going to Search the word problem and determine what I know and need to find:

The dimensions of the basketball court at the park are represented by a width of $2 x+6$ and a length of $x+4$.

Draw a polynomial expression to represent the area of the basketball court. Remember today we will multiply the binomials together, but instead of using the manipulatives, I will draw pictures of the tiles on the board.

b. Maximize Student Engagement and Monitor Student Understanding: Involve students in the process as you continue to think aloud while demonstrating how to solve the problems (e.g., calling on a student(s) to state the next step after explaining or modeling the first step, group/choral responding).

T: Okay, if the width is going on the top of my corner piece, how many $x$-bars do I need to draw?

S: Two.

T: That's right! Now, I'm going to Translate my problem into a picture form (refer to the second step of the STAR strategy). I am going to draw squares to represent my constants. You tell me when to stop drawing squares.

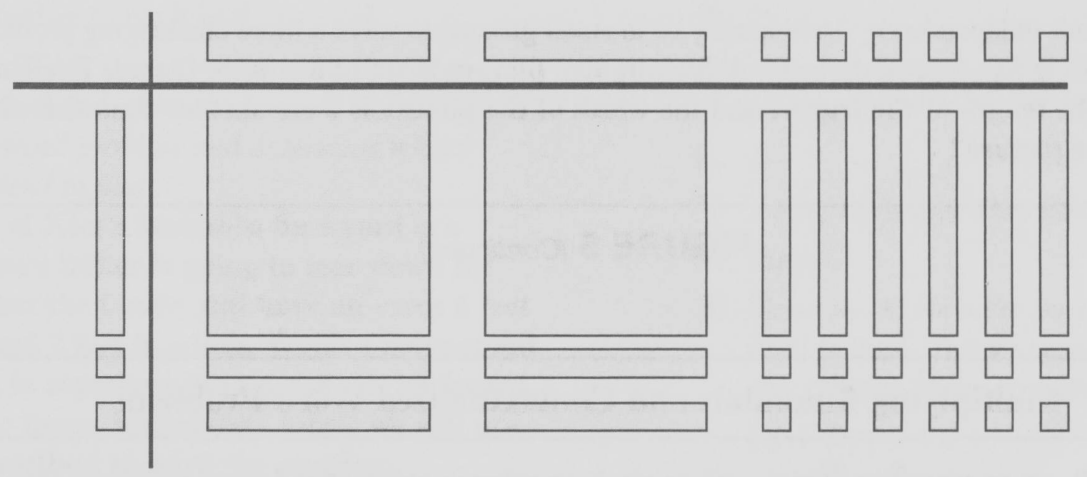

T: Excellent! Now an $x$-bar distributed to, or multiplied by, an $x$-bar equals what?

S: $x^{2}$

T: Great job! And I am drawing a big square that fits nicely between my top and side $x$-bar. Now I am distributing, or multiplying, my top $x$-bar and the side constants. I am going to draw a rectangle to represent my $x$-bar. Give me a thumbsup if that is correct.

T: Thanks for letting me know that I am drawing the right shape! Now let's move on to the second rectangle, that represents an x-bar. And let's distribute, or multiply, that and all of the side shapes. (Teacher continues to model this process for each manipulative on the top of the corner piece.)

T: Now what is the area of our basketball court. Let's say it together as I write it on the board.

S: $2 x^{2}+10 x+12$.

T: Let's review our answer. (Review the word problem and the reasonableness of answer. Provide another example or two if students need additional demonstrations.)

\section{Guided Practice}

a. Provide guidance as students perform 3 or 4 more problems with use of the STAR cue cards and reduce your level of support as students assume more responsibility for the learning (high, medium, low, none). For example (low level of support):

T: Great job helping me solve this problem! Now you are ready to solve a problem with your partner. Remember we are going to draw a representation of the tiles. We are not going to use the tiles. Use your STAR Strategy cue card. Here is our problem:

Our neighborhood swimming pool has a length that is $\mathbf{2}$ meters longer than the width.

On Saturday mornings, a section of the swimming pool is roped off for swimming laps, which makes the pool 
1 meter shorter in width. We need to write an expression to represent the dimensions of the space in the pool which is available for free swim and write a polynomial expression for the area of this space.

T: For this problem we will have negative integers. How will we represent a negative integer in our drawings?

S: Students may suggest shading in the negative integer or drawing a negative symbol in the squares/rectangles that represent a negative number.

T: Great suggestions! You and your partner decide how you would like to represent negative integers and complete the following problem (walk around the room providing corrective feedback and remodeling as needed).

V. Independent Practice: Students will complete additional problems independently (for example, the National Library of Virtual Manipulatives offers numerous lesson ideas and resources to help students visualize multiplying and factoring expressions (see http://nlvm.usu.edu/en/nav/ category_g_4_t_2.html).

VI. Remediation: With a high level of teacher guidance, students will draw pictures of the algebra tiles (and/or return to the use of algebra tiles, as needed for remediation) to practice solving problems addressed during instruction.

The dimensions of the basketball court at the park are represented by a width of $x+2$ and a length of $x+1$. Draw a polynomial expression to represent the area of the basketball court.

VII. Extension: Students work independently (individually or in small groups) to solve a more challenging problem. Students may represent the problem using any type of drawing: A rectangular picture is set in a square frame. The length of the picture is $\mathbf{4} \mathrm{cm}$ shorter than the length of the frame, and the width of the picture is $\mathbf{2} \mathbf{~ c m}$ shorter than the width of the frame. What is the area of the picture?

FIGURE 5 (Continued)

\section{Multiplying Binomials and Contextualized Word Problems}

Objective: Students will use numbers, variables, and symbols to solve contextualized word problems involving binomial expressions with positive and negative terms with $80 \%$ accuracy.

\section{NCTM Standards:}

The learner will engage in problem-solving and representational processes to engage in an algebraic activity with distributed practice in the geometric concept of area. In addition, the learner will communicate mathematically to peers and the teacher concerning the process of solving contextualized word problems involving multiplying binomial expressions with positive and negative terms.

I. Curriculum-Based Assessment and Planning: Teacher assesses students to ensure that they are appropriately placed within the curriculum and plans for instructional alignment (i.e., aligning all lesson components to the learner's needs).

\section{Advanced Organizer}

a. Review Prerequisite Skills: Review necessary preskills as identified in the concrete and semi-concrete phases and review the use of the algebra tiles to represent and solve contextualized problems. For example:

T: For today's warm-up problem, we will draw representations of the tiles to solve this problem:
Our neighborhood swimming pool has a length that is $\mathbf{5}$ meters longer than the width. On Sunday afternoons, a section of the swimming pool is roped off for a water aerobics class. That section makes the pool 3 meters shorter in width. We need to write an expression to represent the dimensions of the space in the pool which is available for free swim and write a polynomial expression for the area of this space.

b. Objective and Link: State the new skill and link to prior knowledge

T: Yesterday we drew pictures of the algebra tiles to help us to multiply binomials to get a polynomial. 
Today, we are going to use only numbers and variables to solve problems.

c. Rationale: Develop rationale for multiplying binomials

T: Great job with your warm-up problem. Who remembers why we used drawings yesterday instead of the tiles to multiply two binomials?

S: Because we can't take tiles with us everywhere.

T: That's right! Everyone has done a great job drawing your tiles, but raise your hand if you think that drawing takes a long time. I agree. So today, we are going to learn a new strategy to multiply two binomials. It is called the FOIL method.

\section{Demonstration}

a. Model Thinking and Action: Think aloud while explaining how to solve the problem using the FOIL method and referring to the STAR cue card.

T: Review the STAR strategy steps with the classboth individual and group responses. I'm going to Search the word problem and determine what I know and need to find:

The shape of Kim's fenced-in backyard is a square. Kim's father is going to tear down the fence, so that the family will have an extra 6 feet in length and 2 feet in width. Write a polynomial expression to represent the area of the backyard without the fence. Remember, today we will use the FOIL method to solve the problem.

b. Maximize Student Engagement and Monitor Student Understanding: Involve students in the process as you continue to think aloud while demonstrating how to solve the problems (e.g., calling on a student(s) to state the next step after explaining or modeling the first step, group/choral responding).

T: Each letter in "FOIL" represents a word that will give us a clue in how to multiply binomials without drawing all of the shapes. Now, remember when we talked about distributing, or multiplying, the top tiles and the side tiles. FOIL is a distributing, or multiplying, process, just like our tiles. This is what I want you to remember about FOIL:

F irsts

$O$ uters

I nners

L asts

Let's solve the problem $(x+6)(x+2)$. In FOIL, the " $F$ " stands for "firsts" and that means we will multiply the first terms in each of the binomials.

What are the first terms in each of our binomials?
S: $x$ and $x$.

T: Excellent! And $x$ times $x$ equals $x^{2}$. Nod your head if you agree. Remember that when we multiplied our $x$-bar by another $x$-bar, we got a big square that represented $x^{2}$.

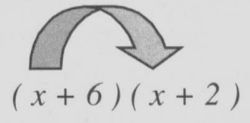

T: Our next letter in FOIL is " $O$ " and it tells us to multiply the outer terms in both binomials, which are the $x$ for the first binomial and the 2 for the second binomial. (Teacher points to the terms.) These are the outer terms, and $x$ times 2 equals what?

$(x+6)(x+2)$

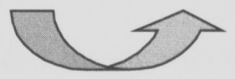

S: $2 x$.

T: Great answer! Now what letter comes next in our strategy?

S: $I$.

T: That's right and what does that mean?

S: Inners.

T: Good work! Now the inner term for the first binomial is the 6. The inner term for the second term is the $x$. What do we do with the $x$ and the 6 ?

$(x+6)(x+2)$

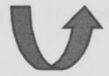

S: Multiply.

T: That's right, and $x$ times 6 equals $6 x$. Just like with our tiles. If we multiplied an $x$-bar times 6 constants, we would get $6 x$-bars. Now our last step in the FOIL strategy is to multiply the last terms in the binomials. What are the last terms of the binomials?

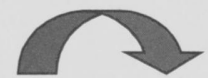

$(x+6)(x+2)$

S: 6 and 2 .

T: Great job finding the last terms! And 6 times 2 equals 12. This is what we have so far.

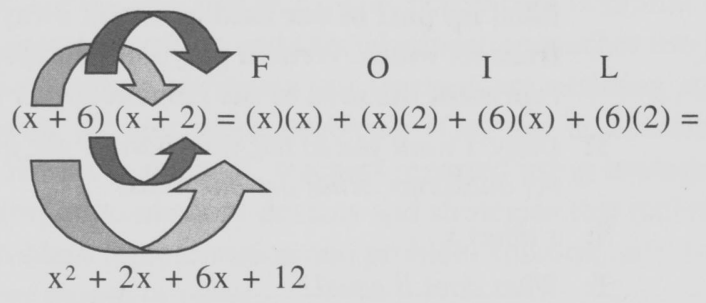


T: Give me a thumbs-up if you think we are finished with our problem, or a thumbs-down if you think we still need to continue.

S: Students give a thumbs-down.

T: That's right! We need to do one more thing. Can we simplify this answer? Are there similar terms that can be added together? Can I add $x^{2}+2 \mathrm{x}$ ? Nod or shake your head to let me know what you all think.

S: Students shake their heads.

T: We can NOT add them together. They are not like terms because they do not have the same exponent. Can we add $2 x+6 x^{2}$ Nod or shake your head to let me know what you think.

S: Students nod their heads.

T: That's right, we can add them together to get $8 x$. So $x^{2}+2 x+6 x+12$ simplifies to $x^{2}+8 x+12$. And this is the final answer to our problem. Let's say it together.

S: $x^{2}+8 x+12$.

T: Great work! Now let's check our work using our calculators. We all have a cue card (See figure 16) to help us learn how to use our calculators to check our answers to problems requiring us to multiply binomials. Let's go through our checklist and check our answer. (Review the word problem and the reasonableness of the answer. Provide another example or two if students need additional demonstrations.)

\section{Guided Practice}

Provide guidance as students perform 3 or 4 more problems with use of the STAR cue cards and reduce your level of support as students assume more responsibility for the learning (high, medium, low, none). For example (medium level of support):

T: Great job helping me solve that problem. Now you are ready to solve a problem with your partner. $(x-5)(x+6)$. Remember to use our new strategy, FOIL. Also remember your STAR strategy. Here's your problem:

The width of our soccer field is $\mathbf{6}$ yards longer than it is wide. After a rainstorm, a huge puddle filled up part of our field and took away 5 yards from its width. Write a polynomial expression to represent the area of the current soccer field.

T: Okay, I want you to tell your partner the answer to my questions. What are our firsts?

S: $x$ times $x$.

T: What does it equal?
S: $x^{2}$.

T: That's right! What are our outers?

S: $x$ times 6.

T: What do they equal?

S: $6 x$.

T: Excellent! What terms are in the inner position? And what do they equal?

S: -5 and $x$ which equals $-5 x$.

T: Great job remembering that the subtraction sign in front of the 5 really means that the 5 is negative, and a negative times a positive is a negative term. Now our final set of terms is the last. What are the terms in the last position of each binomial?

S: Negative 5 and positive 6.

T: And what do they equal when we multiply them together?

S: -30 .

T: Great job! This is what we have so far. Are we finished? Thumbs-up if we are, thumbs-down if we are not.

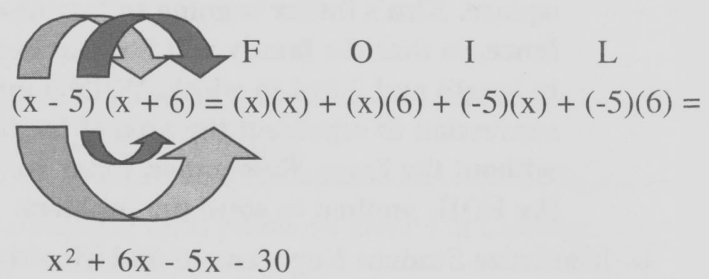

S: Students give a thumbs-down.

T: That's right! What do we have to do to finish this problem?

S: We need to simplify $6 x-5 x$. And our final answer is $x^{2}+x-30$.

T: Excellent work! Now let's check our answer using our calculators. What number should our calculators show us if we have the correct answer?

S: Students hold up one finger

T: You got it! Now let's practice a few more problems. (Walk around the room providing corrective feedback and remodeling as needed.)

\section{Independent Practice}

Provide additional contextualized problems for students to complete independently. Monitor student work and address misconceptions or errors. Review the accuracy of student responses. 


\section{Remediation}

Students will practice multiplying binomials using the FOIL method with teacher guidance using the following website: www.mathwarehouse.com/algebra/polynomials/ foil-method-binomials.php

\section{Extension}

Students will work independently to complete a more challenging problem:

\begin{tabular}{|c|c|c|}
\hline & Roos & \\
\hline & B & b \\
\hline B & BB & $\mathrm{Bb}$ \\
\hline b & $\mathrm{Bb}$ & $\mathrm{bb}$ \\
\hline
\end{tabular}

The Punnet Square displays the possible gene combinations of offspring for a brown roaster and a brown hen. Each parent has half the genes necessary for brown feathers and half the genes necessary for white feathers. The makeup of each parent can be modeled by $0.5 \mathrm{~B}+0.5 \mathrm{~b}$. Their offspring can be modeled by the product of $(0.5 B+0.5 b)$ and $(0.5 B+0.5 b)$. What percentage of the offspring will have a pure brown genotype? A pure white genotype? A hybrid genotype? Refer to the following website for additional examples of Punnet Squares: http://www2.edc.org/weblabs/Punnett/punnettsquares.html

\section{FIGURE 6 (Continued)}

and fractions to middle school students with and without disabilities. Schema-based instruction involves teaching students to identify different problem types or schemas (e.g., compare, group, change). Next, students use the critical features of the word problems and represent the information using a diagram. For example, students determine whether the problem represents a change schema (i.e., adding or subtracting from an initial quantity), a group schema (i.e., combining two different group amounts to obtain a combined amount), or a compare schema (i.e., comparing quantities to determine the difference in the amounts). Lastly, students solve the word problem by planning, solving, and checking the answer (see Figure 7 for an example).

Candi is 31 years old. Joe is 13 years older than Candi.

How old is Joe?

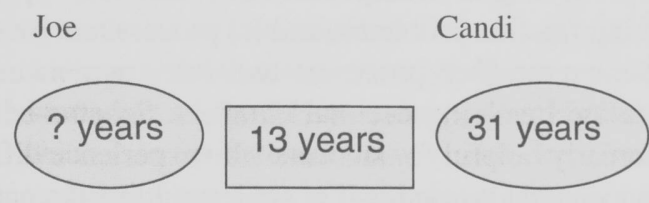

Compared set Difference set Referent set

Total is not known, so add $31+13=44$. Joe is 44 years old.

Source: Adapted from Jitendra, 2002, p. 36

FIGURE 7

Example compare word problems
SI can effectively be coupled with mnemonic strategy instruction in math, in which students use a systematic method to help recall and retain math facts or processes over time. Mnemonic strategies in math include first-letter mnemonic strategies to help students remember and apply steps for solving math problems. Other process mnemonics may include the use of metaphors to help students remember processes and rules associated with computation (Manalo et al., 2000). The use of metaphors (i.e., relating the processes involved with decimal computation to familiar and interesting stories and actions) used in the process mnemonic condition helps students with math $L D$ to retain the steps over time (Manalo et al., 2000). The authors noted (p. 153) that "instead of trying to remember the correct procedures through numbers and symbols they had previously dealt with unsuccessfully, the.students had metaphors incorporating the warrior stories and actions." Test and Ellis (2005) also found that implementation of a first-letter mnemonic helped students with math $\mathrm{LD}$ retain information over time.

In a promising finding, $85 \%$ of the JC teachers reported using strategies that address problem-solving steps either daily or weekly (see Figure 8). This percentage is similar to math general education and special education teacher use in general education settings when teachers are assisting students with solving word problems (Gagnon \& Maccini, 2007). However, many JC teachers reported using strategies that incorporate memory devices and strategies that include both problem representation and problem solution only 1-4 times per month or never.

The teachers who reported not using SI strategies commonly indicated that the practice does not meet their student's 


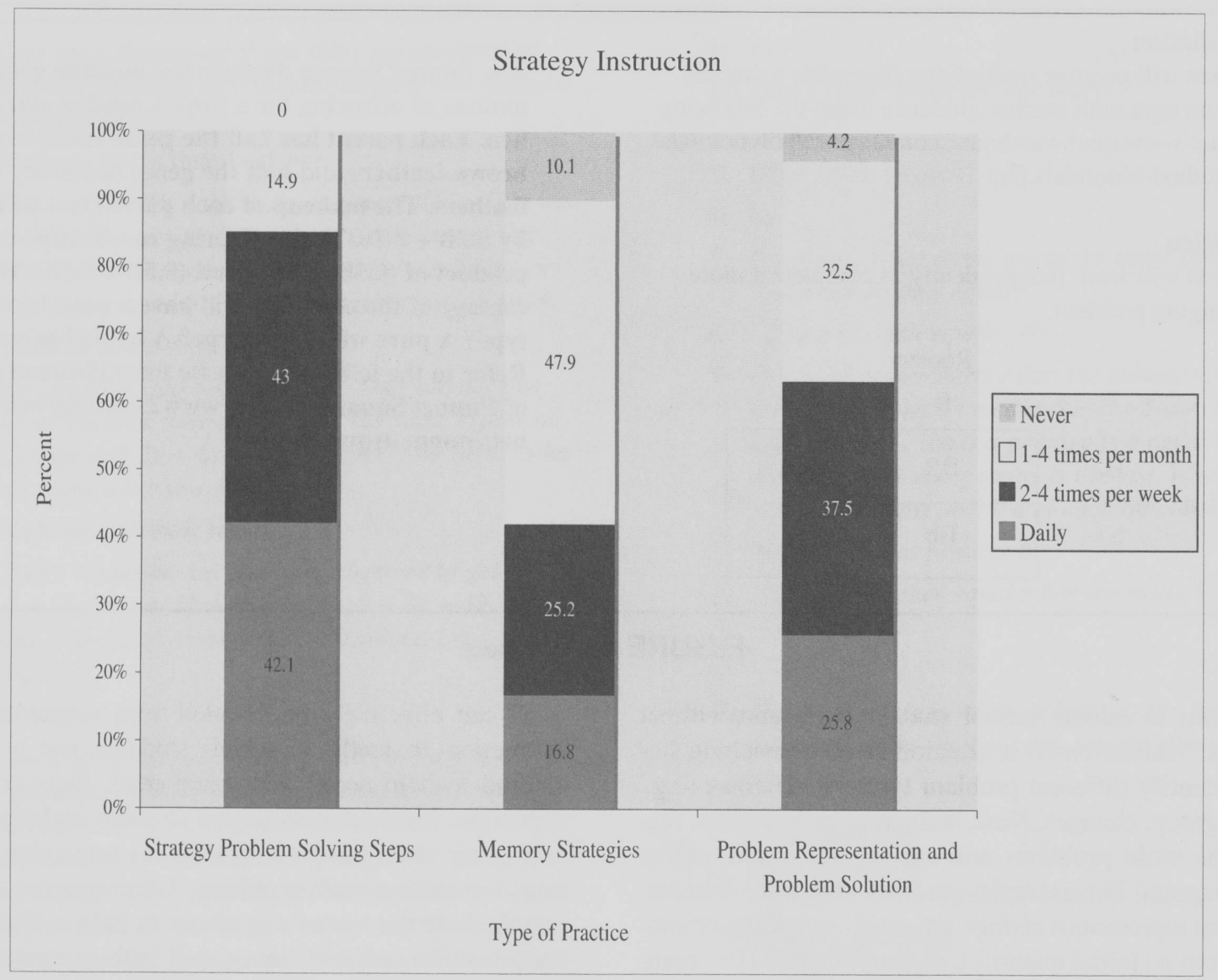

\section{FIGURE 8 \\ Percentage of use of variables of strategy instruction reported}

academic needs. This reason is in direct contrast to the research that documents the effects of SI with secondary students with difficulties in math across a variety of settings (Jitendra et al., 1999, 2002; Xin et al., 2005; Manalo et al., 2000; Test \& Ellis, 2005). The next most frequent reason for not using SI was the need for more training, followed by the need for materials and resources. As with the other instructional approaches mentioned, SI does not require extensive materials or funding for implementation. To assist with training and resource information, we describe an example of a first-letter mnemonic strategy, STAR, in the following section and provide an illustration of implementation within the three lessons plans (see Figures 4, 5, and 6). We also provide a list of recommended resources for use of SI.

\section{Implications for Practice}

SI is effective for helping middle school students with LD and EBD learn problem solving involving addition, subtraction, multiplication, division, and proportion (Jitendra et al., 1999, 2002; Xin et al., 2005), decimals (Manalo et al.,
2000); and fractions (Test \& Ellis, 2005), particularly when used in small group learning environments (i.e., resource rooms, separate classrooms). Across educational settings, students benefit from (a) schema-based SI to help them represent problems and solve for solutions; (b) first-letter mnemonic strategies to help them remember and apply steps for solving fraction problems; and (c) process mnemonics to help them remember processes and rules associated with computation involving decimal numbers. Schema-based SI is particularly helpful for students who experience difficulty with conceptual knowledge (i.e., understanding the nature of the problem) and methods for solving for the solution. The schema-based SI approach incorporates systematic instruction with structure identity (i.e., multiplicative compare and proportion), representation via a diagrammatic structure relevant to the problem type, and problem solution based on the completed diagram (Xin et al., 2005).

As Figure 9 shows, the STAR strategy integrates many of the variables found to be effective in the SI literature, including (a) using a first-letter mnemonic to help students 


\section{STAR Strategy}

1. S earch the word problem

a. Read the problem carefully.

b. Ask yourself questions: "What facts do I know?" and "What do I need to find out?"

c. Write down facts.

2. T ranslate the words into a mathematical equation.

a. Choose a variable.

b. Identify the operation(s).

c. Represent the problem with Algebra Lab Gear (concrete). Draw a picture of the representation (semi-concrete). Write an algebraic equation (abstract).

3. A nswer the problem.
a. Using Algebra Lab Gear (concrete)
b. Using picture representation (semi-concrete)
c. Apply rule for integers (abstract)

4. $\mathrm{R}$ eview the problem.
a. Reread the problem.
b. Ask question, "Does the answer make sense? Why?"
c. Check answer.

\section{FIGURE 9 STAR Strategy implementing the CSA strategy (Maccini \& Hughes, 2000)}

remember essential problem-solving steps: (b) teaching both problem representation and problem solution to address conceptual understanding; (c) using methods of di (model, guided practice, independent practice, feedback, and review) to systematically teach the strategy; and (d) selfmonitoring with use of structured worksheets (as described in the Instructional Adaptations section). The sample lesson plans illustrate use of the STAR strategy (see Figures 4, 5, and 6), which is used in combination with the aforementioned instructional practices to facilitate student acquisition and generalization of the strategy. The resources listed below address using SI in math for secondary students with disabilities.

\section{STRATEGY INSTRUCTION RESOURCES}

\section{Suggested Readings:}

American Institutes for Research. (2004). Learning strategies and mathematics. Washington, DC: Author. Retrieved March
31, 2008, from http://www.k8accesscenter.org/training_resourc es/LearningStrategies_Mathematics.asp

$\checkmark$ American Institutes for Research. (2004). Using mnemonic instruction to teach math. Washington, DC: Author. Retrieved March 31, 2008, from http://www.k8accesscenter.org/training resources/mnemonics_math.asp

$\checkmark$ Jitendra, A. (2002). Teaching students math problem-solving through graphic representations. Teaching Exceptional Children, 34(4), 34-38.

$\checkmark$ Maccini, P., \& Gagnon, J. C. (2005). Mathematics Strategy Instruction (SI) for middle school students with learning disabilities. Washington, DC: American Institutes for Research. Retrieved March 31, 2008, from http://www.k8accesscenter. org/training_resources/massini.asp

$\checkmark$ Montague, M. (2005). Math problem solving for middle school students with disabilities. Washington, DC: American Institutes for Research. Retrieved March 31, 2008, from http://www.k8 accesscenter.org/training_resources/MathProblemSolving.asp

\section{Technology and Real-World Problem Solving}

\section{Definition}

Technology-based instructional approaches include use of the computer (e.g., computer-assisted instruction [CAI], computer tutorials) and other types of specialized systems (e.g., video, web-based instruction, media) that support student learning (Vergason \& Anderegg, 1997). For example, videodisc or DVD-based instruction incorporates interactive learning and effective design components to support student learning. Real-world activities focus on embedding the problem-solving information within real-world contexts to enhance student conceptual knowledge, participation, and generalization (Polloway \& Patton, 1997). Both technology and real-world problem solving are advocated in the NCTM standards (NCTM, 2000) as essential components for mathematics instruction.

\section{Research Base}

Studies have documented the positive effects resulting from the use of technology and real-world problem solving with secondary students classified as LD and EBD in settings that range from general education to alternative settings (Bottge, 1999; Bottge, Heinrichs, Chan, \& Serlin, 2001; Bottge, Heinrichs, Mehta, \& Hung, 2002; Bottge, Rueda, LaRoque, Serlin, \& Kwon, 2007; Bottge, Rueda, Serlin, Hung, \& Kwon, 2007). Additionally, the combination of technology and real-world problem solving are highly recommended with some of our most troubled youth, such as those in JC school settings (Gagnon \& Mayer, 2004; Maccini et al., 2006). Overall, studies on technology and real-world problem solving demonstrated significant gains in problem solving involving adding and subtracting whole numbers and fractions (Bottge, 1999), algebra skills and 
concepts (e.g., nonlinear functions, slope, reliability, measurement error) (Bottge et al., 2001; Bottge, Rueda, Laroque, et al., 2007; Bottge, Rueda, Serlin, et al., 2007), percents, measurement, whole and mixed fractions, and estimation (Bottge et al., 2002; Bottge, Rueda, Serlin, et al., 2007).

Several studies examined the effects of Enhanced Anchored Instruction (EAI). EAI involves embedding or "anchoring" math to real-world problem-solving situations via videodisc or $\mathrm{CD}$ with subsequent application of the targeted math concepts to a student-based project (e.g., building a skateboard ramp, constructing and racing derby cars, constructing wooden benches, building a compost bin). The studies were adapted from research at Vanderbilt University that included a series of 12 math story problems on videodiscs called The New Adventures of Jasper Woodbury (Learning Technology Center at Vanderbilt University, 1996). In another example (Bottge et al., 2002), students in the EAI condition worked in small groups to solve story problems presented on the videodisc, Fraction of a Cost. The vignette shows middle school students planning and developing a skateboard ramp given a budget and collected materials. Students navigated through the video and solved problems and related subproblems involving measurement skills, fractions, and money. The teacher reviewed concepts and facilitated student learning as they navigated the video. As an application to the skills learned, students then designed and built wooden benches for the school. Bottge and colleagues found that students in the EAI condition performed better than students not receiving the intervention on contextualized problem-solving tasks. EAI students also were better able to maintain performance and/or generalize to other problem-solving tasks.

Generally, the literature documents the positive impact of technology-based practices anchored in real-world mathematics problem-solving tasks for secondary students. The results show promise for students with disabilities when specific supports are provided. For example, in two of the studies, researchers noted certain cognitive supports necessary to assist students with disabilities, including multimedia-based (i.e., replaying segments, revising graphs, using virtual tape measures) and instructional assistance (i.e., timely teacher-directed instruction, observation of peers as models to inform practice).

Despite the empirical support for using technology and real-world problem solving on a daily or weekly basis, more than $30 \%$ of the teachers in JC schools reported using technology-based practices (CAI, web-based, and real-world application) monthly, if at all (see Figure 10). In fact, only half of teachers reported using CAI and three-fourths of teachers reported using web-based practices either sometimes or never. This use is consistent with teacher-reported practice in general education settings, as secondary general education math and special education teachers noted using technology (e.g., graphing calculators) 2-4 times or less per month (Gagnon \& Maccini, 2007). The most prominent reason JC teachers reported not using specific types of technology-based practices and real-world problem solving was lack of materials/resources. Lack of materials was also reported by general education math teachers in general education settings as a barrier to implementing goals consistent with the NCTM standards (Maccini \& Gagnon, 2002). Math teachers within JC settings may have certain constraints, including security issues with online access and lack of fiscal supports for technology (Leone \& Meisel, 1997; Maccini et al., 2006). However, proper teacher supervision can prevent inappropriate computer use such as surfing the web, and security issues should not prevent youth from being provided appropriate mathematics instruction that includes technology and real-world problem solving. In the next section, we discuss resources and materials for teachers to consider that take into account certain restrictions in JC settings, as well as research-based recommendations for use regardless of setting.

\section{Implications for Practice}

Current literature documents the positive impact of technology-based practices anchored to real-world mathematics problem-solving tasks for secondary students with and without disabilities. Although the practices are promising, at least half of the teachers in the current survey who reported not using the practices noted not having the necessary materials or resources. Similarly, results of a National Center for Education Statistics survey (USDOE, 1999) showed that a number of teachers reported certain barriers to computer use for instruction, including lack of computers. Teachers within JC settings may be particularly vulnerable to these barriers given (a) the lack of fiscal resources for purchasing technology and related materials within JC programs (Leone \& Meisel, 1997) and (b) supervision concerns with web accessibility within JC schools (Maccini et al., 2006).

Given the empirical support and relevance to preparing students for an increasing technological society and workforce, all students, regardless of setting, must be provided with technology-based practices with sound instructional design principles and real-world problem application opportunities. In light of the disparity of resources across schools and districts, state grants or subgrants may be available for purchasing technology to improve student academic performance or to provide professional development for teachers. Also, numerous computer donation websites offer directories or information on companies and agencies that donate used computer hardware to schools and community associations (e.g.,www.change.net/links/computers.htm). The resources 


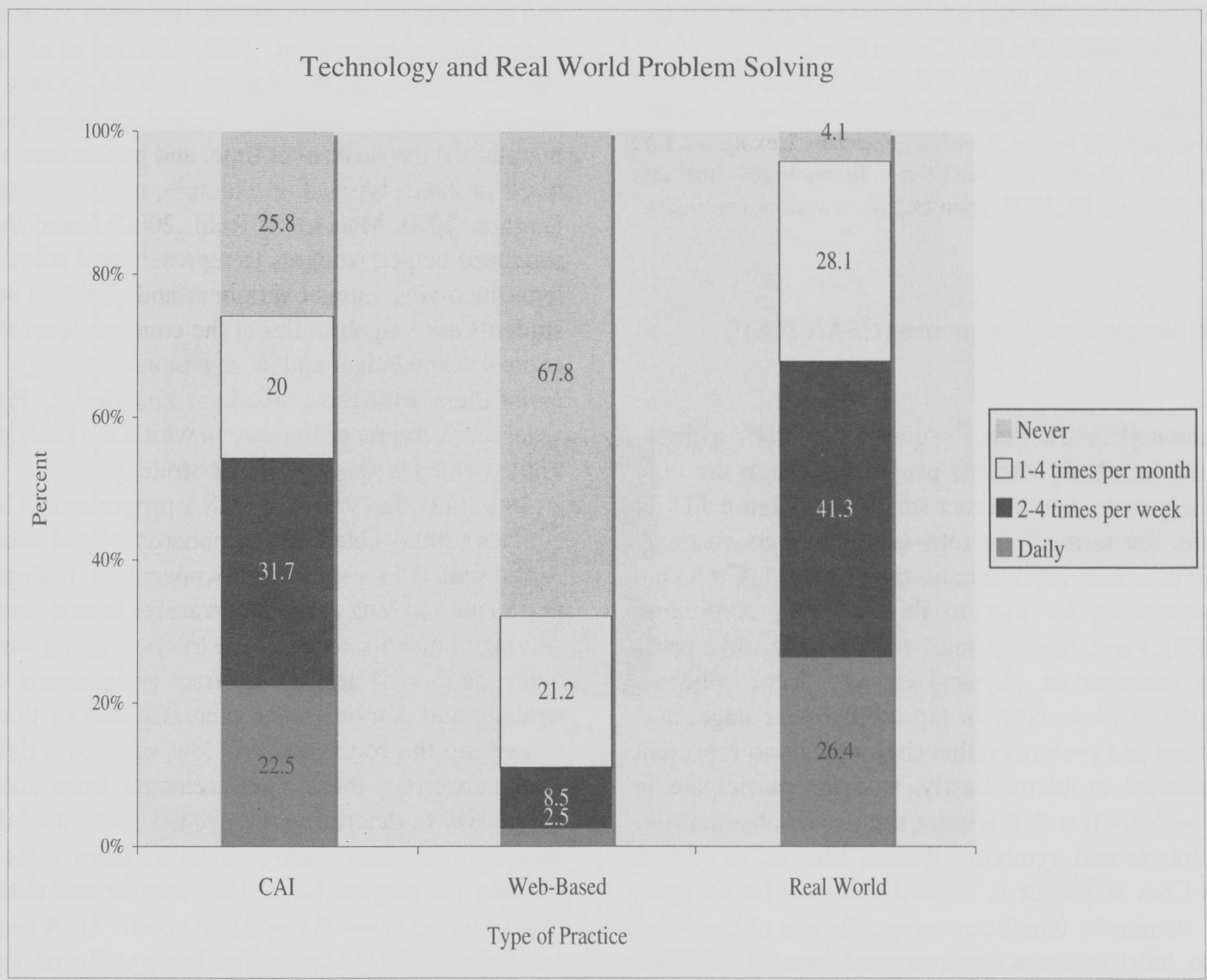

FIGURE 10

Percentage of use of variables of technology and real-world problem solving reported

listed in the next section include access briefs and articles addressing technology-based practices and real-world problem solving in math for secondary students with LD and EBD.

To provide additional assistance to general and special educators across the educational continuum, refer to the lessons plans provided in Figures 4, 5, and 6. These lessons exemplify the embedding of secondary mathematics concepts into real-world situations that are interesting and age-appropriate (e.g., basketball and soccer fields, a swimming pool, construction of a bedroom). Students use graphing calculators and a cue card of steps to check their answers to problems requiring them to multiply binomials (see Figure 16), and the lessons illustrate how an effective strategy such as algebra tiles can be used through technology (e.g., virtual manipulatives). The virtual manipulatives are digital representations of algebra tiles and other manipulatives that can be moved by a mouse, similar to using physical tiles.

\section{TECHNOLOGY AND REAL-WORLD PROBLEM-SOLVING RESOURCES}

\section{Suggested Websites:}

$\checkmark$ Bottge, B. (n.d.) Teaching Enhanced Anchored Mathematics Project: Advancing the math skills of low-achieving adolescents in technology-rich learning environments. Retrieved October 3 , 2007, from http://www.wcer.wisc.edu/TEAM/contact_us.html

$\checkmark$ The Adventures of Jasper Woodbury. (n.d.). Retrieved October 3, 2007, from http://pea body.vanderbilt.edu/projects/funded/ jasper/Jasperhome.html

\section{Suggested Readings:}

$\checkmark$ American Institutes for Research. (2004). Computer-assisted instruction and mathematics. Washington, DC: Author. Retrieved October 10, 2007, from http://www.k8accesscenter.org/ training_resources/LearningStrategies_Mathematics.asp

$\checkmark$ Bottge, B. A. (2001). Building ramps and hovercrafts and improving math skills. Teaching Exceptional Children, 34(1), 16-23.

$\checkmark$ Davis, B., Caros, J., \& Carnine, D. (2006). Using technology to access the general education curriculum. In D. D. Deshler \& J. 
B. Schumaker (Eds). Teaching adolescents with disabilities (pp. 187-234). Thousand Oaks, CA: Corwin Press.

$\checkmark$ Hasselbring, T. S., Lott, A. C., \& Zydney, J. M. (2006). Technology-supported math instruction for students with disabilities: Two decades of research and development. Lexington, KY: University of Kentucky Assistive Technology Institute. Retrieved October 10, 2007, from http://www.ldonline.org/article/6291\#refer

\section{Graduated Instructional Sequence (CSA/CRA)}

\section{Definition}

The graduated instructional sequence involves a threestage process in which students progress through the concrete, semi-concrete, and abstract stages (see Figure 11). In the literature, the terms "concrete-semi-concrete-abstract" (CSA) and "concrete-representational-abstract" (CRA) are used synonymously to refer to this teaching continuum (Witzel, 2005). First, students must successfully solve problems using concrete or physical objects. Next, students advance to the semi-concrete or representational stage, during which they use pictures rather than objects to represent the mathematical problem. Lastly, students participate in mathematical activities that require the use of abstractions, such as numbers and symbols (Witzel, Mercer, \& Miller, 2003). The CSA sequence is aligned with and builds upon the NCTM standards, which encourage the use of hands-on activities to help students explore mathematics (NCTM, 2000).

Several studies on the CSA sequence have reported positive effects with middle and high school students classified as LD and EBD on such challenging skills as integer numbers and geometry. Moreover, researchers have reported the effective use of the CSA sequence in a range of inclusionary

\begin{tabular}{|l|l|}
\hline Concrete & $\begin{array}{l}\text { Use of physical manipulatives, such as } \\
\text { counters, beads, blocks, fraction bars, } \\
\text { pattern blocks, Cuisenaire rods, alge- } \\
\text { bra tiles, and geoboards }\end{array}$ \\
\hline Semi-concrete & $\begin{array}{l}\text { Use of visual representations or draw- } \\
\text { ings, often corresponding to physical } \\
\text { manipulatives. }\end{array}$ \\
\hline Abstract & $\begin{array}{l}\text { Use of numbers, variables, and sym- } \\
\text { bols associated with mathematics. }\end{array}$ \\
\hline
\end{tabular}

FIGURE 11

The concrete-semi-concrete-abstract instructional sequence and more exclusionary settings, including JC schools (Cass, Cates, Smith, \& Jackson, 2003; Maccini et al., 2006; Maccini \& Hughes, 2000; Maccini \& Ruhl, 2000). Within the empirical studies, students reached criterion performance, maintained the skills over time, and generalized to more difficult problem types. For example, researchers (Maccini \& Hughes, 2000; Maccini \& Ruhl, 2000) found that the CSA sequence helped students to represent and solve word problems involving integer numbers and problem solving. The students used algebra tiles at the concrete level to build conceptual knowledge and a mnemonic strategy (STAR) to assist them with the procedural knowledge. Figure 9 provides an overview of the way in which the CSA strategy was implemented within the STAR strategy.

In a study that varied the CSA progression, Cass and colleagues (2003) noted that geoboards helped secondary students with LD establish a conceptual understanding of perimeter and area that could transfer to real-world problem solving. Students received instruction using only the concrete (geoboard) and the abstract components of the CSA strategy and demonstrated generalization of these skills by measuring the room and window sizes of a dollhouse and then converting these measurements from scaled size to actual size to determine the needed amount of flooring and window treatments. Although studies show some support for limiting the progression to the concrete and abstract stages, more support exists for using the entire CSA sequence.

Use of the CSA sequence on a daily or weekly basis helps students across settings understand math concepts via a multisensorial approach prior to advancing to more abstract tasks (Cass et al., 2003; Hudson \& Miller, 2006; Maccini \& Hughes, 2000; Maccini \& Ruhl, 2000). However, as Figure 12 shows, over half of the teachers in JC schools reported using this strategy only monthly, if at all. The infrequent use of the entire CSA sequence in JC schools is consistent with other studies of teachers in public schools (Gagnon \& Maccini, 2007). Teachers in JC schools primarily noted that they needed more training and additional materials and resources to effectively and frequently use the CSA sequence. Like certain teachers in more inclusionary schools, some teachers in juvenile corrections noted that their views of teaching do not match the CSA approach. This disconnection between teachers' views of instruction and CSA may span a variety of classroom settings and could be related to teachers' views that a conceptual, rulebased approach is more appropriate for secondary students. One additional complication inherent in JC school settings is that security concerns may limit a teacher's approach to mathematics instruction. Manipulatives can be a serious security issue. However, specific adaptations to the use of manipulatives can and should be made (Maccini et al., 2006). The implications for practice noted next consider the 


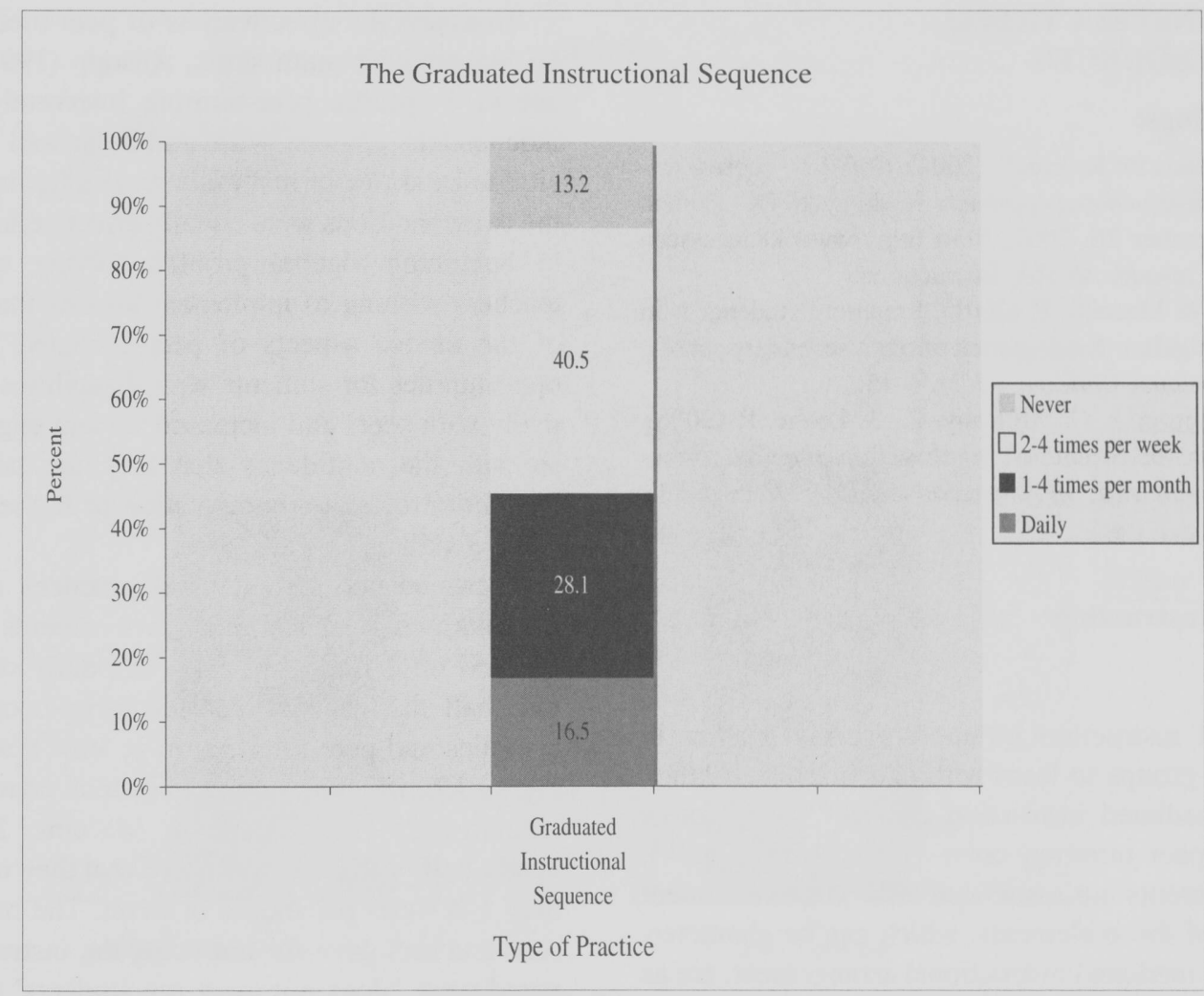

FIGURE 12

Percentage of use of the graduated instructional sequence reported

importance of using CSA in all classroom settings, as well as safety precautions that specific exclusionary settings may require.

\section{Implications for Practice}

Hudson and Miller (2006) recommend the use of a variety of age-appropriate manipulatives (e.g., algebra tiles and geoboards) for secondary students to address conceptual understanding. Teachers in more secure settings may use foam algebra tiles such as Easyshapes Algebra Tiles (EIA Education, 2008) as an alternative resource to help learners represent polynomials using geometric models.

More than half of the teachers in JC schools who reported never using the CSA sequence gave as their reason the need for more training. Therefore, the lesson plans (see Figures 4,5 , and 6) contained in this article include the use of the CSA strategy. Packaging the explicit instructional strategy with the CSA/CRA strategy has been found to be effective in teaching algebraic skills to secondary students with math difficulties. The lessons serve as an abridged version of how the CSA sequence would occur and then describe one day for each stage (concrete, semi-concrete, and abstract).
However, the literature suggests that students reach a criterion of $80 \%$ or higher on two to three consecutive probes (independent practice) before advancing to the next stage within the CSA sequence (Hudson \& Miller, 2006; Maccini \& Hughes, 2000; Maccini \& Ruhl, 2000).

Some teachers mentioned that the CSA approach does not match their view of teaching. However, research clearly indicates the effectiveness of CSA for secondary students with special needs and the positive outcomes related to student understanding of more abstract mathematics. For example, although algebra is an abstract form of mathematics, Maccini and Hughes (2000) and Maccini and Ruhl (2000) provided support for using the CSA sequence when teaching algebra skills from word problems involving subtraction of integers (Maccini \& Ruhl, 2000) to all four computations of integers (Maccini \& Hughes, 2000). Additionally, these researchers suggested a specific algebra manipulative, Algebra Lab Gear (Picciotto, 1990), which are tiles used to represent numeric and variable quantities. The lesson plans provided exemplify how to use the tiles within the CSA sequence. Additional resources are listed in the next section. 


\section{GRADUATED INSTRUCTIONAL SEQUENCE RESOURCES}

\section{Suggested Readings:}

$\checkmark$ American Institutes for Research. (2004). Concrete-representational-abstract instructional approach. Washington, DC: Author. Retrieved September 26, 2007, from http://www.k8accesscen ter.org/training_resources/CRA_Instructional

$\checkmark$ Gagnon, J. C., \& Maccini, P. (2001). Preparing students with disabilities for algebra: Kindergarten through secondary school. Teaching Exceptional Children, 33(2), 8-15.

$\checkmark$ Maccini, P., Gagnon, J. C., Mulcahy, C., \& Leone, P. (2006). Math instruction for committed youth within juvenile correctional schools. Journal of Correctional Education, 57(3), 210-225.

\section{Peer-Mediated Instruction}

\section{Definition}

Peer-mediated instruction groups students together in pairs or in small groups to learn with and from each other. Although peer-mediated instruction can take many forms (e.g., classwide peer tutoring, cross-age tutoring, jigsaw), some critical elements are associated with positive student outcomes. Four of those elements, which can be characteristics of any peer-mediated instructional arrangement, are as follows: (a) students must be assigned roles and trained to function in those roles; (b) students must participate in providing instruction to one another; (c) teachers must provide ongoing monitoring and assistance during instructional sessions; and (d) the instructional task must include an academic and/or social goal (Hall \& Stegila, 2003). Most widely used peer-mediated instructional approaches can be classified broadly as either peer-tutoring (paired) arrangements or cooperative learning groups of 3-6 students. Regardless of configuration, peer-mediated instructional arrangements can benefit students by allowing for increased opportunities to engage actively with the curriculum (Harper \& Maheady, 2007). Peer-mediated instruction also allows students to practice interacting with peers in a structured, supervised setting.

Peer-mediated instruction has been associated with positive outcomes for students with LD and EBD in a wide variety of content areas, including mathematics (see Baker, Gersten, \& Lee, 2002). While less research has assessed the effectiveness of peer-mediated instruction in mathematics at the secondary level than the elementary level, the research that does exist shows promise. For example, Calhoon and Fuchs (2003) determined that a peer-tutoring intervention, combined with curriculum-based measurement, was effective for teaching computations to secondary students with $\mathrm{LD}$ and EBD on the mathematics within self-contained classrooms in three regular public high schools.
To assess the effectiveness of peer-mediated instruction on higher-order math skills, Allsopp (1997) compared the use of a specific peer-tutoring intervention to traditional independent practice with middle school students considered to be at risk of math failure. His findings indicated that the two conditions were equally effective in producing gains in beginning algebra problem-solving skills. Therefore, teachers wishing to implement lessons that take advantage of the unique aspects of peer-mediated instruction (e.g., opportunities for students with disabilities to interact positively with peers and increased student engagement) can do so with the confidence that they are not compromising instruction of either computation or higher-order problemsolving skills.

Peer-mediated instructional practices are effective for students across educational environments and are recommended on a frequent basis (i.e., daily or weekly). More than half the teachers reported using cooperative learning activities and peer tutoring on at least a weekly basis (see Figure 13), which is similar to general education teachers in regular settings (Gagnon \& Maccini, 2007). However, nearly half of the teachers noted that they used the practices only $1-4$ times per month or never. The most frequent reasons teachers gave for not using the instructional practices noted were "does not meet my students' academic needs" and the need for more training. However, for those who reported the practice does not meet their students' academic needs, as noted, the practice has been proven to be effective for teaching both computation or higher-order problemsolving skills (Allsopp, 1997; Calhoon \& Fuchs, 2003). To assist teachers with ideas for implementation, the following recommendations for practice are provided.

\section{Implications for Practice}

Teachers who indicated that peer-mediated instructional arrangements do not meet their students' academic needs may not understand the potential benefits of peer-mediated instructional techniques or the importance of incorporating specific instructional elements into the academic tasks. For example, to realize maximum benefit from peer-mediated instruction, teachers should assign students to roles and train them in these roles (Malmgren, 1999). Teachers also should ensure that students work together on tasks that include specific math instructional goals. Additionally, it is important for teachers to stay actively engaged during the activity and provide ongoing monitoring and assistance throughout the session. Not adhering to these suggestions may limit the effectiveness of peer-mediated instructional sessions, leading teachers to view peer activities as a generally ineffective approach. 


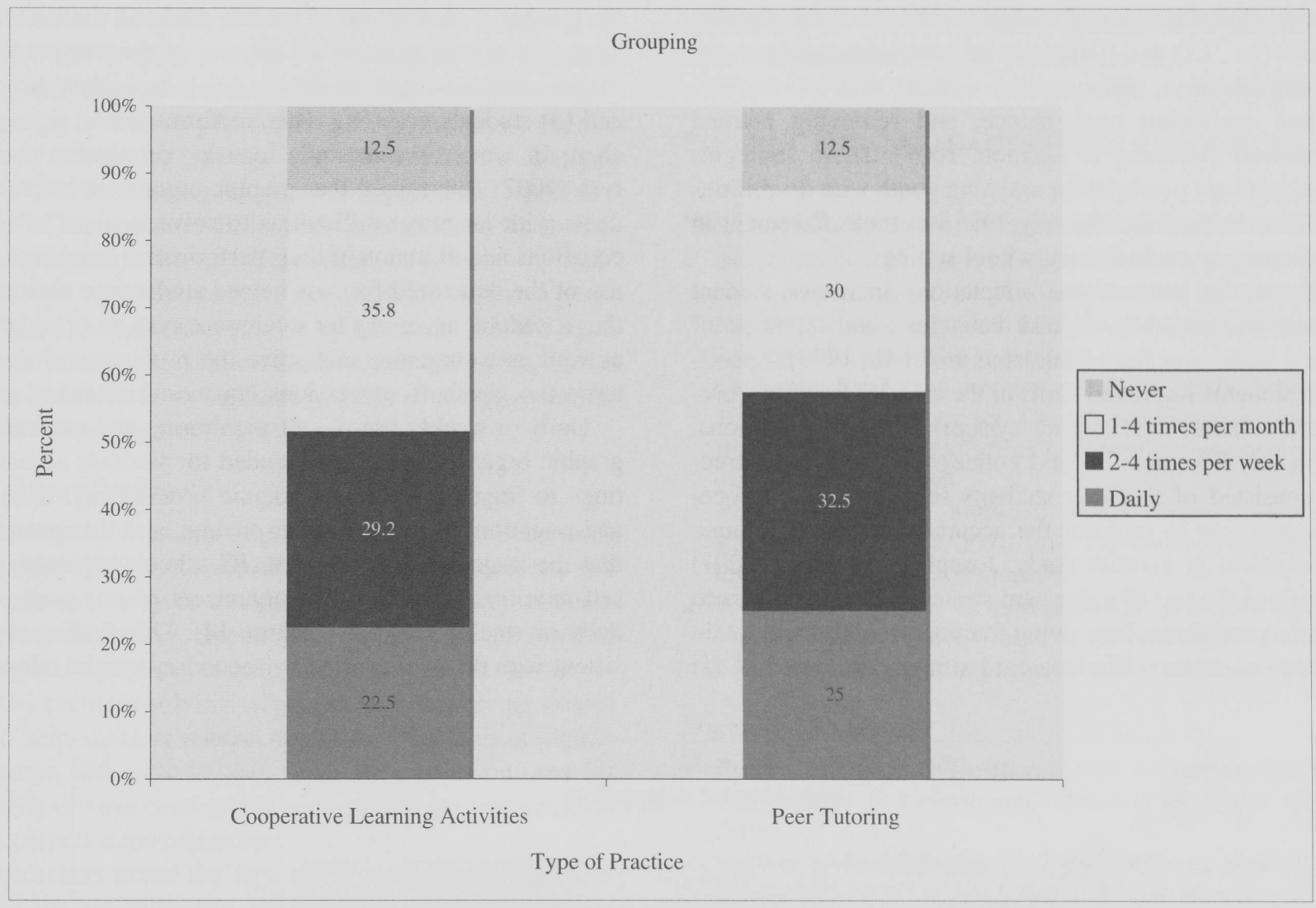

\section{FIGURE 13 \\ Percentage of use of grouping practices reported}

\section{PEER-MEDIATED INSTRUCTION RESOURCES}

\section{Suggested Readings:}

$\checkmark$ American Institutes for Research. (2004). Using peer tutoring for math. Washington, DC: Author. Retrieved April 10, 2008, from http://www.k8accesscenter.org/training_resources/math peertutoring.asp

$\checkmark$ Bender, W. N. (2005). Differentiating math instruction: Strategies that work for $\mathrm{K}-8$ classrooms! Thousand Oaks, CA: Corwin Press.

$\checkmark$ LD Online. (1997). Using cooperative learning to teach mathematics to students with learning disabilities. Arlington, VA: Author. Retrieved April 10, 2008, from http://www.ldonline. org/sitecontact

\section{Instructional Adaptations}

\section{Definition}

This final section includes a description of three types of instructional adaptations involving self-monitoring of academic tasks, graphic organizers, and cue cards for helping students with disabilities in math. Self-monitoring of academic tasks refers to methods teachers use to help learners track or graph their work completed or level of performance (Shimabukuro, Prater, Jenkins, \& Edelen-Smith, 1999). Graphic organizers are pictorial displays or diagrams that represent essential content relationships using graphic features (e.g., stems, arrows, boxes) and various structures (e.g., cause and effect, hierarchical, sequencing, Venn diagrams, webs). Much like graphic organizers, cue cards or structured worksheets serve as prompts to help students remember information, such as specific steps listed on a card or worksheet to represent and solve math problems (Joseph \& Hunter, 2001).

Research has documented the positive effects of selfmonitoring and cue cards or graphic organizers (Ives, 2007; Joseph \& Hunter, 2001; Shimabukuro et al., 1999) in math with middle and high school students with LD. Researchers have evaluated the effects of these approaches within public and private school self-contained classrooms. However, researchers also recommend using both self-monitoring and cue cards or graphic organizers in JC settings (Maccini et al., 2006). The use of self-monitoring is important, given 
common characteristics of students with high incidence disabilities (i.e., LD and EBD) in math, including problems in focusing attention, metacognitive deficits such as monitoring and evaluating performance, and retrieving learned information (Mulcahy \& Gagnon, 2007). These strategies hold significant potential for assisting youth with disabilities to achieve in mathematics, regardless of their placement in inclusionary or exclusionary school settings.

Use of the instructional adaptations increases student productivity, accuracy, on-task behaviors, and retention of learned skills over time (Shimabukuro et al., 1999). Specifically, students improved skills in the areas of fractions, prealgebra content, and solving systems of linear equations. Within the Shimabukuro and colleagues research, instruction consisted of teaching students self-monitoring procedures and how to monitor the accuracy of their academic performance. In another study, Joseph and Hunter (2001) determined the use of a cue card strategy helped students to learn the procedures for solving fraction problems and retain the steps over time. The cue card strategy consisted of (a) the teacher modeling use of the cue card and the associated steps; (b) guided practice of the use of the cue card with sample problems and feedback; (c) independent practice; and (d) students graphing daily performance on a progress chart. In a more recent study focusing on algebra content, Ives (2007) determined that graphic organizers helped students with language difficulties to solve systems of linear equations and to maintain their performance over time. The use of the structured formats helped students to understand the procedures necessary for solving the systems of equations, as well as to organize and solve the problems using math terms (i.e., symbols, expressions, equations) instead of words.

Daily or weekly use of self-monitoring and cue cards or graphic organizers is recommended for students across settings to improve student academic productivity, accuracy, and retention of information over time, and it is promising that the majority of teachers in JC schools reported using self-monitoring and graphic organizers or cue cards on a daily or weekly basis (see Figure 14). This finding is consistent with the use reported by secondary special education

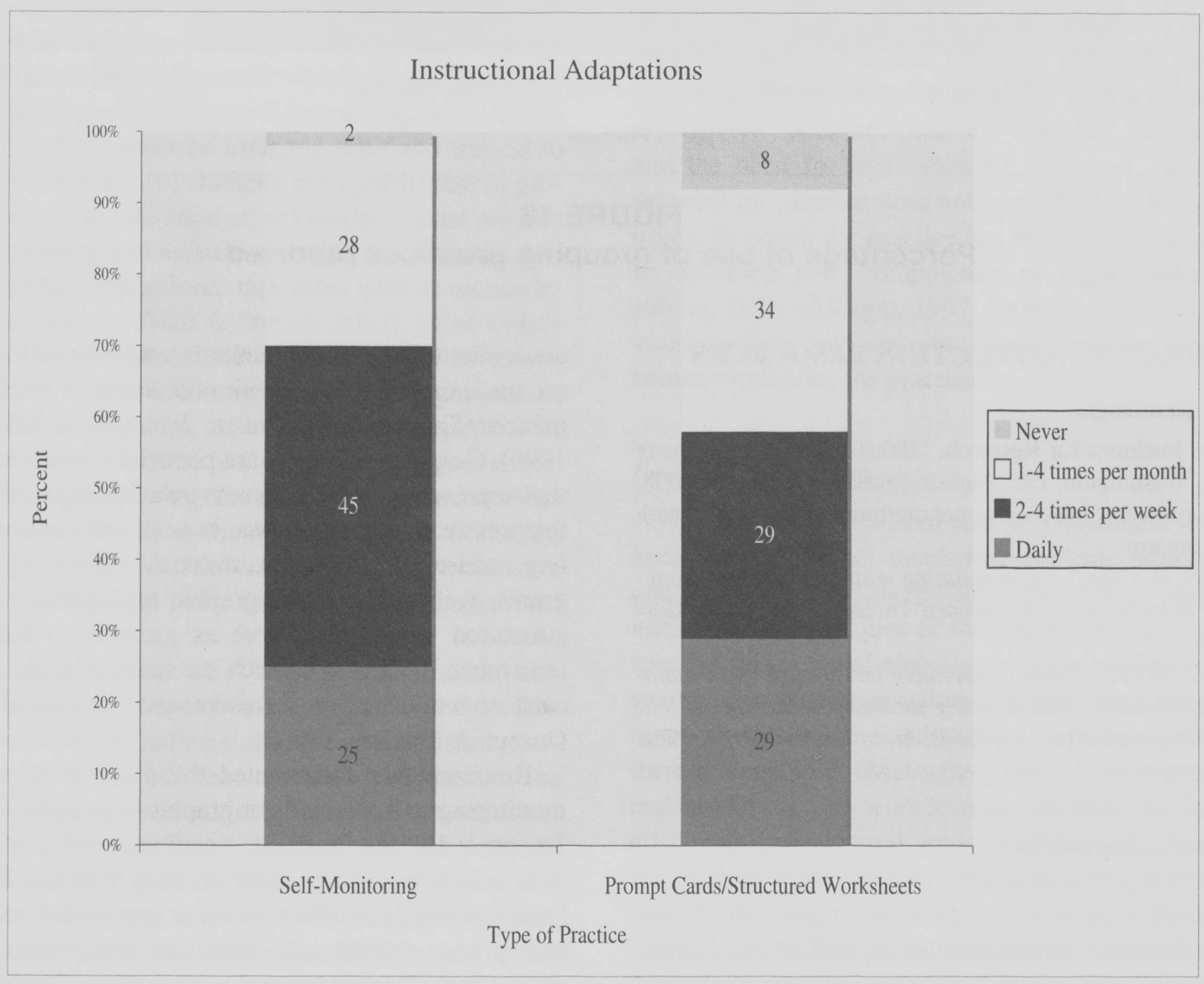

FIGURE 14 
math teachers in general education settings (Gagnon \& Maccini, 2007). Still, a cause for concern is that approximately one third of the teachers reported using the techniques only 1-4 times per month or never. As noted, the use of a self-monitoring strategy may be helpful for students with EBD when solving complex math problems, especially in light of the common difficulties these students have with focusing attention during independent activities.

Teachers who reported not using the instructional practices noted the lack of materials or resources and the need for more training. To support teachers across settings, in the section that follows we describe ways in which teachers can overcome these barriers.

\section{Implications for Practice}

The current literature supports the use of instructional adaptations such as self-monitoring, graphic organizers, and cue cards on a daily or weekly basis for secondary students with math difficulties. Specifically, teachers should provide (a) graphic organizers to help students organize and recall essential problem-solving steps; (b) self-monitoring strategies to help students independently monitor their academic production and accuracy and focus their attention; and (c) cue cards or structured worksheets to help prompt students to use correct steps/procedures.

As teachers noted the lack of resources and training as reasons for not using the practices, the specific resources provided here include online resources with examples of graphic organizes, blank organizers, and lesson ideas, as well as links to additional research and articles containing examples of teachers implementing the practices with secondary students. Additionally, Figure 15 and sample lessons (see Figures 4, 5, and 6) provide examples of the practical

\begin{tabular}{|l|l|}
\hline Strategy Questions & $\begin{array}{l}\text { Write a check }(\checkmark) \text { after } \\
\text { completing each task or } \\
\text { question }\end{array}$ \\
$\begin{array}{l}\text { Search the word problem: } \\
\text { Read the problem carefully }\end{array}$ & \\
$\begin{array}{l}\text { Ask yourself: "What do I } \\
\text { know? What do I need to } \\
\text { find?" }\end{array}$ & \\
Write down facts: & \\
\hline
\end{tabular}

Sources: Maccini \& Gagnon, 2001; Maccini \& Hughes, 2000: Maccini \& Ruhl, 2000. application of a self-monitoring procedure in conjunction with a structured worksheet (see Figure 15).

\section{INSTRUCTIONAL ADAPTATIONS RESOURCES}

\section{Suggested Websites of Math Graphic Organizers:}

$\checkmark$ Beanblossom, J. E. (2007, October). Southwest Georgia RESA: Math graphic organizers. Retrieved October 30, 2007, from http://www.sw-georgia.resa.k12.ga.us/Math.html\#High\%20 School\%20Graphic\%20Organizers

$\checkmark$ California Technology Assistance Project. (2007, February). Middle school math project: Graphic organizer resource. Retrieved October 30, 2007, from http://www.ctap4.org/math/di_ graphic_organizers.htm

$\checkmark$ Enchanted Learning Software. (n.d.). Graphic organizers. Retrieved October 11, 2007, from http://www.enchantedlearn ing.com/graphicorganizers/math/

$\checkmark$ Teacher Vision. (n.d.). Graphic organizers and resources. Retrieved October 11, 2007, from http://www.teachervision.fen. $\mathrm{com} /$ slideshow/graphic-organizers/52116.html?detoured=1

\section{Suggested Readings:}

$\checkmark$ Bender, W. (2005). Differentiating math instruction: Strategies that work for $K-8$ classrooms! Thousand Oaks, CA: Corwin Press.

$\checkmark$ Gagnon, J. C., \& Maccini, P. (2001). Preparing students with disabilities for algebra: Kindergarten through secondary school. Teaching Exceptional Children, 33(2), 8-15.

$\checkmark$ Maccini, P., \& Gagnon, J. C. (2005). Math graphic organizers for students with learning disabilities. Washington, DC: American Institutes for Research. Retrieved March 31, 2008, from http://www.k8accesscenter.org/training_resources/mathgraphic organizers.asp

\section{SUMMARY}

Reform efforts have called for high-quality math instruction based on use of empirically validated practices and ageappropriate math curriculum (IDEA, 2004), as well as a greater emphasis on conceptual knowledge (i.e., understanding the math concepts as opposed to facts), and problem solving and reasoning skills (NCTM, 1989; 2000). These recent legislative mandates apply to all students, including those with disabilities educated in alternative settings such as juvenile correctional facilities.

In response to this call, this article provides ideas that would be effective across various educational settings. Survey results revealed teachers' current views and application of research-based instructional practices. The examples and resources presented here constitute an attempt to address teacher understanding and assist teachers in delivering an effective instructional program that will support students in gaining competence in math. 


\section{Checking our Answers when Multiplying Binomials Using a TI-83/TI-83+/TI-84+ Graphing Calculator}

1. Enter the answer to your problem.

2. Set "=" by
a. $2^{\text {nd }}$ function
b. MATH
c. TEST \#1
d. Hit ENTER

3. Enter the two binomials

\begin{tabular}{|l|}
\multicolumn{1}{c|}{ SET "=" } \\
\hline TEST LOGIC \\
$1:=$ \\
$2: \neq$ \\
$3:>$ \\
$4: \geq$ \\
$5:<$ \\
$6: \leq$ \\
\hline
\end{tabular}

4. Hit ENTER

5. If a 1 appears, the answer IS correct.

6. If a 0 appears, the answer is NOT correct.

Example: $(x+3)(x+4)=x^{2}+7 x+12$

1. To enter $x^{2}$,
a. Hit ALPHA
b. X is located on the key STO
c. Hit $x^{2}$

2. $\mathrm{Hit}+$

3. Hit 7

4. To enter $x$

a. Hit ALPHA

5. Hit +

b. X is located on the key STO

6. Hit 12

7. Set "="
a. $2^{\text {nd }}$ function
b. MATH
c. TEST \#1
a. Hit ENTER

8. Hit $(x+3)(x+4)$

Remember to enter $x$ by ALPHA, STO

9. Hit ENTER

10. If a 1 appears, the answer IS correct. If a 0 appears, the answer is NOT correct. Use the FOIL method again to correct your problem.

$$
\mathrm{x}^{2}+7 \mathrm{x}+12=(\mathrm{x}+3)(\mathrm{x}+4)
$$

This is correct! 


\section{REFERENCES}

The Adventures of Jasper Woodbury. (n.d.) Retrieved October 3, 2007, from http://peabody.vanderbilt.edu/projects/funded/jasper/Jasper home.html

Allsopp, D. H. (1997). Using classwide peer tutoring to teach beginning algebra problem-solving skills in heterogeneous classrooms. Remedial and Special Education, 18, 367-379.

American Institutes for Research. (2004). Computer-assisted instruction and mathematics. Washington, DC: Author. Retrieved October 10, 2007, from http://www.k8accesscenter.org/training_reso urces/LearningStrategies_Mathematics.asp

American Institutes for Research. (2004). Concrete-representationalabstract instructional approach. Washington, DC: Author. Retrieved September 26, 2007, from http://www.k8accesscenter. org/training_resources/CRA_Instructional

American Institutes for Research. (2004). Learning strategies and mathematics. Washington, DC: Author. Retrieved March 31, 2008, from http://www.k8accesscenter.org/training_resources/Learning Strategies_Mathematics.asp

American Institutes for Research. (2004). Using mnemonic instruction to teach math. Washington, DC: Author. Retrieved March 31, 2008, from http://www.k8accesscenter.org/training_resources/ mnemonics_math.asp

American Institutes for Research. (2004). Using peer tutoring for math. Washington, DC: Author. Retrieved April 10, 2008, from http://www.k8accesscenter.org/training_resources/mathpeertutor ing.asp

Amrein, A. A., \& Berliner, D. C. (2002). High-stakes testing, uncertainty, and student learning. Education Policy Analysis Archives, 10(18). Retrieved February 22, 2008, from http://epaa.asu.edu/ epaa/v10n18/

Baker, S., Gersten, R., \& Lee, D. (2002, September). A synthesis of empirical research on teaching mathematics to low-achieving students. Elementary School Journal, 103(1), 51-73.

Baldi, S., Jin, Y., Skemer, M., Green, P.J., \& Herget, D. (2007). Highlights from PISA 2006: Performance of U.S. 15-Year-Old Students in Science and Mathematics in an International Context (NCES 2008-016). National Center for Education Statistics, Institute of Education Sciences, U.S. Department of Education. Washington, D.C.

Beanblossom, J. E. (2007, October). Southwest Georgia RESA: Math graphic organizers. Retrieved October 30, 2007, from http:// www.sw-georgia.resa.k12.ga.us/Math.html\#High\%20School\%20 Graphic\%20Organizers

Bender, W. N. (2005). Differentiating math instruction: Strategies that work for K-8 classrooms! Thousand Oaks, CA: Corwin Press.

Bley, N. S., \& Thornton, C. A. (1995). Teaching mathematics to students with learning disabilities (3rd ed.). Austin, TX: Pro-Ed.

Bottge, B. (n.d.) Teaching Enhanced Anchored Mathematics Project: Advancing the math skills of low-achieving adolescents in technology-rich learning environments. Retrieved October 3, 2007, from http://www.wcer.wisc.edu/TEAM/contact_us.html

Bottge, B. (1999). Effects of contextualized math instruction on problem solving of average and below-average achieving students. Journal of Special Education, 33(2), 81-92.

Bottge, B. A. (2001). Building ramps and hovercrafts and improving math skills. Teaching Exceptional Children, 34(1), 16-23.

Bottge, B. A., Heinrichs, M., Chan, S., \& Serlin, R. C. (2001). Anchoring adolescents' understanding of math concepts in rich problem solving environments. Remedial and Special Education, 22(5), 299-314

Bottge, B. A., Heinrichs, M., Chan, S., Mehta, Z. D., \& Watson, E. (2003). Effects of video-based and applied problems on the procedural math skills of average- and low-achieving adolescents. Journal of Special Education Technology, 18(2), 5-22.

Bottge, B. A., Heinrichs, M., Chan, S., \& Serlin, R. C. (2001). Anchoring adolescents' understanding of math concepts in rich problem solving environments. Remedial and Special Education, 22(5), 299-314

Bottge, B. A., Heinrichs, M., Mehta, Z. D., \& Watson, E. (2002). Weighing the benefits of anchored math instruction for students with disabilities in general education classes. Journal of Special Education, 35(4), 186-200.

Bottge, B. A., Rueda, E., LaRoque, P. T., Serlin, R. C., \& Kwon, J. M. (2007). Integrating reform-oriented math instruction in special education settings. Learning Disabilities Research \& Practice, 22, 96-109.

Bottge, B., Rueda, E., Serlin, R. C., Hung, Y., \& Kwon, J. M. (2007). Shrinking achievement differences with anchored math problems: Challenges and possibilities. Journal of Special Education, 4l(1), $31-49$.

Bryant, D. P., Bryant, B. R., \& Hammill, D. D. (1990). Characteristic behaviors of students with LD who have teacher-identified math weaknesses. Journal of Learning Disabilities, 33, 168-177.

Bryant, D. P., Kim, S. A., Hartman, P., \& Bryant, B. (2006). Standardsbased mathematics instruction and teaching middle school students with mathematical disabilities. In K. R. Harris \& S. Graham (Series Eds.) and M. Montague \& A. K. Jitendra (Eds.), Teaching mathematics to middle school students with learning difficulties (Vol. XXX, pp. 7-28). New York: Guilford Press.

Bybee, R. W., \& Stage, E. (2005). No country left behind. Issues in Science \& Technology, 21(2), 69-75.

Calhoon, M. B., \& Fuchs, L. (2003). The effects of peer-assisted learning strategies and curriculum-based measurement on the mathematics performance of secondary students with disabilities. Remedial and Special Education, 24(4), 235-245.

California Technology Assistance Project. (2007, February). Middle school math project: Graphic organizer resource. Retrieved October 30, 2007, from http://www.ctap4.org/math/di_graphic_orga nizers.htm

Cass M., Cates, D., Smith, M., \& Jackson, C. (2003). Effects of manipulative instruction on solving area and perimeter problems by students with learning disabilities. Learning Disabilities Research \& Practice, 18(2), 112-120.

Cawley, J. F., \& Miller, J. H. (1989). Cross-sectional comparisons of the mathematics performance of children with learning disabilities: Are we on the right track towards comprehensive programming? Journal of Learning Disabilities, 22, 250-254.

Coffey, O. D., \& Gemignani, M. G. (1994). Effective practices in juvenile correctional education: A study of the literature and research, 1980-1992. Washington, DC: U.S. Department of Justice, National Office for Social Responsibility.

Davis, B., Caros, J., \& Carnine, D. (2006). Using technology to access the general education curriculum. In D. D. Deshler \& J. B. Schumaker (Eds). Teaching adolescents with disabilities (pp. 187-234). Thousand Oaks, CA: Corwin Press.

EIA Education. (2008). Easyshapes Algebra Tiles. Oakland, NJ Author. Retrieved July 20, 2008, from http://www.eaieducation. com/532290.html 
Ellis, E. S., \& Lenz, B. K. (1996). Perspectives on instruction in learning strategies. In D. D. Deshler, E. S. Ellis, \& B. K. Lenz (Eds.), Teaching adolescents with learning disabilities (2nd ed., pp. 9-60). Denver, CO: Love.

Enchanted Learning Software. (n.d.). Graphic organizers. Retrieved October 11, 2007, from http://www.enchantedlearning.com/graph icorganizers/math/

Gagnon, J. C., Barber, B. R., \& Van Loan, C. L. (2008). Characteristics and curriculum policies and practices in juvenile correctional schools. Unpublished manuscript.

Gagnon, J. C., \& Bottge B. (2006). Mathematics instruction in secondary interim, short- and long-term alternative placements. Preventing School Failure, 51(1), 39-47.

Gagnon, J. C., \& Maccini, P. (2001). Preparing students with disabilities for algebra: Kindergarten through secondary school. Teaching Exceptional Children, 33(2), 8-15.

Gagnon, J. C., \& Maccini, P. (2005). Direct instruction in middle school mathematics for students with learning disabilities. Washington, DC: American Institute for Research. Retrieved March 31, 2008, from http://www.k8accesscenter.org/training_resources/ directinstruction math.asp

Gagnon, J. C., \& Maccini, P. (2007). Teacher use of empirically-validated and standards-based instructional approaches in secondary mathematics. Remedial \& Special Education, 28, 43-56.

Gagnon, J. C., \& Mayer, M. (2004). Educating juveniles with disabilities in correctional settings. In L. M. Bullock, R. A. Gable, \& K. J. Melloy (Eds.), Fifth CCBD mini-library series (pp. 1-59). Arlington, VA: Council for Children with Behavioral Disorders.

Garnett, K., \& Fleishchner, J. E. (1983). Automatization and basic fact performance of normal and learning disabled children. Learning Disability Quarterly, 6, 223-231.

Gonzales, P., Guzmán, J. C., Partelow, L., Pahlke, E., Jocelyn, L., Kastberg, D., \& Williams, T. (2004). Highlights from the Trends in International Mathematics and Science Study (TIMSS) 2003 (NCES 2005-005). U.S. Department of Education, National Center for Education Statistics. Washington, DC: U.S. Government Printing Office.

Hall, T., \& Stegila, A. (2003). Peer mediated instruction and intervention. Wakefield, MA: National Center on Accessing the General Curriculum. Retrieved April 3, 2008, from http://www.cast.org/ publications/ncac/ncac_peermii.html

Harper, G. F., \& Maheady, L. (2007). Peer-mediated teaching and students with learning disabilities. Intervention in School and Clinic, 43(2), 101-107.

Hasselbring, T. S., Lott, A. C., \& Zydney, J. M. (2006). Technologysupported math instruction for students with disabilities: Two decades of research and development. Lexington, KY: University of Kentucky Assistive Technology Institute. Retrieved October 10, 2007, from http://www.ldonline.org/article/6291\#refer

Hudson, P., \& Miller, S. P. (2006). Designing and implementing mathematics instruction for students with diverse learning needs. Boston: Pearson Education.

Individuals With Disabilities Education Act of 2004. Pub. L. No. 108446.

Ives, B. (2007). Graphic organizers applied to secondary algebra instruction for students with learning disorders. Learning Disabilities Research \& Practice, 22(2), 110-118.

Jitendra, A. (2002). Teaching students math problem-solving through graphic representations. Teaching Exceptional Children, 34(4), 34-38.
Jitendra, A. K., DiPipi, C. M., \& Perron-Jones, N. (2002). An exploratory study of schema-based word-problem instruction for middle school students with learning disabilities: An emphasis on conceptual and procedural understanding. Journal of Special Education, 36(1), 23-38.

Jitendra, A. K., Hoff, K., \& Beck, M. M. (1999). Teaching middle school students with learning disabilities to solve word problems using a schema-based approach. Remedial and Special Education, 20(1), 50-64.

Joseph, L. M., \& Hunter, A. D. (2001). Differential application of a cue card strategy for solving fraction problems: Exploring instructional utility of the cognitive assessment system. Child Study Journal, 31(2), 123-136.

LD Online. (1997). Using cooperative learning to teach mathematics to students with learning disabilities. Arlington, VA: Author. Retrieved April 10, 2008, from http://www.ldonline.org/sitecontact

Learning Technology Center at Vanderbilt University. (1996). The new adventures of Jasper Woodbury [Videodisc]. Mahwah, NJ: Erlbaum.

Lee, J., Grigg, W., \& Dion, G. (2007). The Nation's Report Card: Mathematics 2007 (NCES 2007-494). Washington DC: U.S. Department of Education, National Center for Education Statistics.

Leone, P. E., \& Meisel, S. (1997). Improving education services for students in detention and confinement facilities. Children's Legal Rights Journal, 71(1), 2-12.

Maccini, P., \& Gagnon, J. C. (2002). Perceptions and applications of NCTM standards by special and general education teachers. Exceptional Children, 68(3), 325-344.

Maccini, P., \& Gagnon, J. C. (2005). Math graphic organizers for students with learning disabilities. Washington, DC: American Institutes for Research. Retrieved March 31, 2008, from http://www.k8 accesscenter.org/training_resources/mathgraphicorganizers.asp

Maccini, P., \& Gagnon, J. C. (2005). Mathematics Strategy Instruction (SI) for middle school students with learning disabilities. Washington, DC: American Institutes for Research. Retrieved March 31, 2008, from http://www.k8accesscenter.org/training_resources/ massini.asp

Maccini, P., \& Gagnon, J. C. (2008). Math curriculum and instruction in juvenile correctional facilities: Results of a national survey. Unpublished manuscript.

Maccini, P., Gagnon, J. C., Mulcahy, C., \& Leone, P. (2006). Math instruction in juvenile corrections. Journal of Correctional Education, 57(3), 210-229.

Maccini, P., \& Hughes, C. A. (1997). Mathematics interventions for adolescents with learning disabilities. Learning Disabilities Research \& Practice, 12, 165-176.

Maccini, P., \& Hughes, C. A. (2000). Effects of a problem solving strategy on the introductory algebra performance of secondary students with learning disabilities. Learning Disabilities Research \& Practice, 15(1), 10-21.

Maccini, P., Mulcahy, C., \& Wilson, M. G. (2007). A follow-up of mathematics interventions for secondary students with learning disabilities. Learning Disabilities Research \& Practice, 22(1), 58-74.

Maccini, P., \& Ruhl, K. L. (2000). Effects of graduated instructional sequence on the algebraic subtraction of integers by secondary students with disabilities. Education and Treatment of Children, 23(4), 465-489.

Malmgren, K. (1999). Cooperative learning as an academic intervention for students with mild disabilities. Focus on Exceptional Children, 31(5), 1-9. 


\title{
naW
}

\section{Strategies for Teaching Students With Special Needs} Methods and Techniques for Classroom Instruction

\author{
KATHLEEN M. MCCOY
}

The target audience for this book is elementary teachers who teach in inclusive settings with special needs children in their class. The focus is on reading evaluation and reading methods, literacy in the language arts, mathematics evaluation and mathematics instruction, and ideas for the social aspects of inclusion.

The book gives proven methods, practical guidelines, and new innovations for classroom instruction. Vignettes, key terms, the IEP process, and informal assessment are all part of this new text. It also covers low-incidence and high-incidence disabilities and creative ideas for managing and organizing classroom time.

The author and the contributors are highly experienced professionals with classroom teaching backgrounds.

\section{Special Features}

- Provides nuts-and-bolts ideas for teachers to enhance organizational skills.

- Provides numerous suggestions and examples for conducting informal assessment.

- Shows classroom activities to facilitate success in both academic and social experiences in the schools and the community.

- Special focus on reading methods showing interventions, strategies, and the perfect literacy model for the needs of the student. 
Manalo, E., Bunnell, J. K., \& Stillman, J. A. (2000). The use of process mnemonics in teaching students with mathematics learning disabilities. Learning Disability Quarterly, 23(2), 137-156.

Maryland State Department of Education. (2008). 2008 Maryland Report Card. Baltimore, MD. Retrieved September 24, 2008, from http://msp.msde.state.md.us/

Montague, M. (2005). Math problem solving for middle school students with disabilities. Washington, DC: American Institutes for Research. Retrieved March 31, 2008, from http://www.k8access center.org/training_resources/MathProblemSolving.asp

Mulcahy, C., \& Gagnon, J. C. (2007). Teaching mathematics to secondary students with emotional/behavioral disorders. In L. M. Bullock \& R. A. Gable (Eds.), Seventh CCBD mini-library series (pp. 1-36). Arlington, VA: Council for Children with Behavioral Disorders.

National Council of Teachers of Mathematics. (1989). Curriculum and evaluation standards for school mathematics. Reston, VA: Author.

National Council of Teachers of Mathematics. (2000). Principles and standards for school mathematics. Reston, VA: Author.

No Child Left Behind Act of 2001, Pub. L. No. 107-110, 115 Stat. 1425 (2002).

Organization for Economic Cooperation and Development (2003). Program for International Student Assessment. Paris: Author.

Organization for Economic Cooperation and Development (2004). Learning for tomorrow's world: First results from PISA 2003. Paris: Author.

Ozaki, C., Williams, R. L., \& McLaughlin, T. F. (1996). Effects of a copy/cover/compare drill and practice for multiplication facts mastery with a sixth grade student with learning disabilities. B. $C$. Journal of Special Education, 20(2), 65-74.

Parmar, R. S., Cawley, J. F., \& Frazita, R. R. (1996). Word problem solving by students with and without mild disabilities. Exceptional Children, 62, 415-429.

Picciotto, H. (1990). The algebra lab. Sunnyvale, CA: Creative Publications.

Polloway, E. A., \& Patton, J. R. (1997). Strategies for teaching learners with special needs (6th ed.). Upper Saddle River, NJ: PrenticeHall.

Prentice Hall. (2002). Connected mathematics program. New York, NY: Author.

Quinn, M. M., Rutherford, R. B., Leone, P. E., Osher, D., \& Poirier, J. M. (2005). Youth with disabilities in juvenile corrections: A national survey. Exceptional Children, 71, 339-345.
Rosenshine, B., \& Stevens, R. (1986). Teaching functions. In M.C. Wittrock (Ed.), Handbook of research on teaching (3rd ed., pp. 376-391). New York: MacMillan.

Scarlato, M. C., \& Burr, W. A. (2002). Teaching fractions to middle school students. Journal of Direct Instruction, 2(1), 23-38.

Shimabukuro, S. M., Prater, M. A., Jenkins, A., \& Edelen-Smith, P. (2000). The effects of self-monitoring of academic performance on students with learning disabilities and ADD/ADHD. Education and Treatment of Children, 22(4), 397-414.

Teacher Vision. (n.d.). Graphic organizers and resources. Retrieved October 11, 2007, from http://www.teachervision.fen.com/slide show/graphic-organizers/52116.html?detoured $=1$

Test, D. W., \& Ellis, M. F. (2005). The effects of LAP fractions on addition and subtraction of fractions with students with mild disabilities. Education and Treatment of Children, 28(1), 11-24.

U.S. Department of Education (1999). Teachers' tools for the 21 st century: A report on teachers' use of technology. (NCES 2000-102). Washington, DC: National Center for Education Statistics.

U.S. Department of Education. (2007). Twenty-seventh annual report to congress on the implementation of the Individuals with Disabilities Education Act, Vol. 1 Washington, DC: Author.

U. S. Department of Education, National Center for Education Statistics (2000). Teacher use of computers and the Internet in public schools. Washington, DC: Author.

Vergason, G. A., \& Anderegg, M. L. (1997). Dictionary of special education and rehabilitation (4th ed.). Denver, CO: Love.

Witzel, B. S., Mercer, C. D., \& Miller, M. D. (2003). Teaching algebra to students with learning difficulties: An investigation of an explicit instruction model. Learning Disabilities Research \& Practice, 18(2), 121-131.

Witzel, B. (2005). Using CRA to teach algebra to students with math difficulties in inclusive settings. Learning Disabilities: A Contemporary Journal, 3(2), 49-60.

Woodward, J. (2004). Mathematics education in the United States: Past to present. Journal of Learning Disabilities, 37(1), 16-31.

Xin, Y. P., Jitendra, A. K., \& Deatline-Buchman, A. (2005). Effects of mathematical word problem solving instruction on middle school students with learning problems. Journal of Special Education, 39(3), 181-192. 